\title{
Organization of Cortical and Thalamic Input to Pyramidal Neurons in Mouse Motor Cortex
}

\author{
Bryan M. Hooks, ${ }^{1}$ Tianyi Mao, ${ }^{1}$ Diego A. Gutnisky, ${ }^{1}$ Naoki Yamawaki, ${ }^{2}$ Karel Svoboda, ${ }^{1}$ and Gordon M. G. Shepherd ${ }^{1,2}$ \\ ${ }^{1}$ Janelia Farm Research Campus, Howard Hughes Medical Institute, Ashburn, Virginia 20147, and ${ }^{2}$ Department of Physiology, Feinberg School of Medicine, \\ Northwestern University, Chicago, Illinois 60611
}

Determining how long-range synaptic inputs engage pyramidal neurons in primary motor cortex (M1) is important for understanding circuit mechanisms involved in regulating movement. We used channelrhodopsin-2-assisted circuit mapping to characterize the longrange excitatory synaptic connections made by multiple cortical and thalamic areas onto pyramidal neurons in mouse vibrissal motor cortex (vM1). Each projection innervated vM1 pyramidal neurons with a unique laminar profile. Collectively, the profiles for different sources of input partially overlapped and spanned all cortical layers. Specifically, orbital cortex (OC) inputs primarily targeted neurons in L6. Secondary motor cortex (M2) inputs excited neurons mainly in L5B, including pyramidal tract neurons. In contrast, thalamocortical inputs from anterior motor-related thalamic regions, including VA/VL (ventral anterior thalamic nucleus/ventrolateral thalamic nucleus), targeted neurons in L2/3 through L5B, but avoided L6. Inputs from posterior sensory-related thalamic areas, including POm (posterior thalamic nuclear group), targeted neurons only in the upper layers (L2/3 and L5A), similar to inputs from somatosensory (barrel) cortex. Our results show that long-range excitatory inputs target vM1 pyramidal neurons in a layer-specific manner. Inputs from sensory-related cortical and thalamic areas preferentially target the upper-layer pyramidal neurons in vM1. In contrast, inputs from 0C and M2, areas associated with volitional and cognitive aspects of movements, bypass local circuitry and have direct monosynaptic access to neurons projecting to brainstem and thalamus.

\section{Introduction}

Motor cortex (M1) plays roles in both internally generated ("volitional") and sensory-driven behaviors. Exemplifying volitional control, animals can learn to regulate M1 activity to gather reward, without generating movements (Fetz, 1969; Schieber, 2011; Koralek et al., 2012), and M1 is activated during imagined movements (Porro et al., 1996; Jeannerod and Frak, 1999). Alternatively, M1 neurons exhibit sensory activity (Ferezou et al., 2007; Hatsopoulos and Suminski, 2011; Murray and Keller, 2011; Huber et al., 2012) and are involved in active sensation (Hill et al., 2011; Petreanu et al., 2012) and sensorimotor learning (Asanuma, 1981; Rokni et al., 2007).

M1 is innervated by axons from thalamus and from frontal and parietal cortex. Input from primary somatosensory (barrel) cortex (S1) (Reep et al., 1990; Hoffer et al., 2003) excites pyrami-

Received Sept. 11, 2012; revised Nov. 6, 2012; accepted Nov. 14, 2012.

Author contributions: B.M.H., T.M., D.A.G., N.Y., K.S., and G.M.G.S. designed research; B.M.H., T.M., D.A.G., and N.Y. performed research; B.M.H. and D.A.G. analyzed data; B.M.H., K.S., and G.M.G.S. wrote the paper.

This work was supported by the Visiting Scientist program of Janelia Farm Research Campus and funded in part by a grant from the National Institutes of Health (National Institute of Neurological Disorders and Stroke, NS061963). We thank Ben Suter, Leopoldo Petreanu, Jianing Yu, Tsai-wen Chen, Nuo Li, Wendy Zhang, and other members of the Svoboda and Shepherd laboratories for comments and suggestions.

The authors declare no competing financial interests or other conflicts of interest.

Correspondence should be addressed to either of the following: Dr. Bryan M. Hooks, Janelia Farm Research Campus, Howard Hughes Medical Institute, 19700 Helix Drive, Ashburn, VA 20147, E-mail: hooksm@janelia.hhmi.org; or Dr. Gordon M. G. Shepherd, Department of Physiology, Feinberg School of Medicine, Morton 5-660, 303 E. Chicago Avenue, Chicago, IL 60611, E-mail: g-shepherd@northwestern.edu.

T. Mao's present address: Vollum Institute, Oregon Health \& Science University, Portland, OR 97239.

DOI:10.1523/JNEUROSCI.4338-12.2013

Copyright $\odot 2013$ the authors $\quad 0270-6474 / 13 / 330748-13 \$ 15.00 / 0$ dal neurons primarily in upper layers of M1 (Kaneko et al., 1994; Kaneko et al., 2000; Mao et al., 2011). Somatosensory information also reaches M1 via higher-order sensory thalamus, including the medial subdivision of posterior nucleus (POm) (Deschênes et al., 1998; Ohno et al., 2012) and ventrolateral thalamus (VL) (Strick and Sterling, 1974; Asanuma et al., 1979; Asanuma et al., 1980; Nambu et al., 1988; Kuramoto et al., 2009). Motor thalamus consists of several nuclei, including the anteromedial (AM), ventral anterior (VA), and ventrolateral (VL) nuclei (Kuramoto et al., 2009; Tlamsa and Brumberg, 2010). Frontal cortical areas also project to M1 (Muakkassa and Strick, 1979; Reep et al., 1990; Rouiller et al., 1993; Dum and Strick, 2002) and may activate M1 during voluntary movements, in contrast to circuits involved in sensory-guided actions (Haggard, 2008; Smith et al., 2010). However, the layers and cell types engaged by these different corticocortical and thalamocortical inputs are largely unknown.

Individual layers of M1 contain neurons with characteristic long-range projections (Peters and Jones, 1984; Molyneaux et al., 2007). Upper layers (L2/3 and L5A) contain intratelencephalic (IT)-type neurons, which project to cortex and striatum. L5B harbors both IT-type neurons and all pyramidal tract (PT)-type neurons, which project to the brainstem and spinal cord, with collaterals to striatum and thalamus. L6 contains corticothalamic (CT)-type neurons and some IT-type neurons. Describing the laminar targeting of inputs to M1 thus provides an understanding of how these distinct output pathways are excited. Of particular interest are the sources of excitatory input to pyramidal neurons in L5B, because these 
Table 1. Injection coordinates

\begin{tabular}{lcll}
\hline Target & A-P & M-L & D-V \\
\hline Motor thalamus & -0.45 & 0.85 & 3.25 \\
Sensory thalamus & -1.2 & 1.3 & 2.75 \\
Frontal cortex (M2) & 2.7 & 0.9 & $0.8 / 0.5$ \\
Orbital cortex & 2.6 & 1.0 & $1.7 / 2.0$ \\
vM1 & 1.05 & 0.9 & $0.8 / 0.5$ \\
Pons & -4.0 & 0.75 & $4.2 / 4.5$ \\
\hline
\end{tabular}

Stereotaxic injections were performed at P12-P16 for sCRACM experiments. Distances are in mm along the anterior/ posterior (A-P) axis, relative to bregma, with positive values anterior to bregma; along the medial/lateral (M-L) axis, relative to the midline; and, in dorsal/ventral (D-V) axis, relative to pia. Where two depths are listed, injections were made at both depths.

include PT-type neurons projecting directly to subcerebral motor circuits.

Here, we used channelrhodopsin-2 (ChR2)-assisted circuit mapping (Petreanu et al., 2007, 2009; Cruikshank et al., 2010) to characterize the specificity with which long-range inputs monosynaptically excite pyramidal neurons in different layers of primary vibrissal motor cortex (vM1) (Mao et al., 2011). We mapped input from two thalamic regions and two frontal cortical areas. Excitation from each pathway entered vM1 with a unique laminar profile. Subcerebral projection neurons in vM1 were directly and selectively excited by inputs from the two frontal cortical areas and anterior thalamus.

\section{Materials and Methods}

Stereotactic injections. Animal protocols were approved by Institutional Animal Care and Use Committees at Janelia Farm Research Campus and Northwestern University. Experimental procedures were similar to previous studies (Petreanu et al., 2009; Mao et al., 2011). C57BL/6 mice of either sex (Charles River) were anesthetized using isoflurane and placed in a custom stereotactic apparatus. Juvenile mice at P12-P16 were injected with ChR2-expressing virus (AAV, serotype $2 / 1$ or $2 /$ rh 10 , referred to as ChR2-XFP in the text; UPenn Vector Core) expressing ChR2-Venus or ChR2-tdTomato (www.addgene.com; plasmids 20071 and 28017). In one experiment (see Fig. 11), adult mice were injected with AAV (serotype 2/1) expressing EGFP (www.addgene.com; plasmid 28014). A small craniotomy was opened with a dental drill, and injections were made with a pulled glass pipette using a custom-made positive displacement pump. Stereotactic coordinates are listed in Table 1. A pair of injections (20-40 $\mathrm{nl}$ each; 500 and $800 \mu \mathrm{m}$ deep) was made into the cortex. One bolus $(20-40 \mathrm{nl})$ was injected into thalamic targets. These injection volumes were required to infect thalamic relay neurons sufficiently strongly for mapping experiments but often led to ChR2 expression in more than one thalamic nucleus. In one experiment (Fig. 1), ChR2 was transfected by in utero electroporation to L2/3 neurons as previously described ( $\mathrm{Pe}-$ treanu et al., 2009). For experiments recording from retrogradely labeled neurons, the tracer (red or green fluorescent microbeads; LumaFluor) was injected following AAV injection during the surgery (see Figs. 8, 10). In other experiments, these tracers were coinjected to mark the injection site. In other cases, fluorescent microbeads were used to trace retrograde pathways (see Figs. 3, 11).

Electrophysiology and photostimulation. Brain slices were prepared 11-24 d after viral infection, in young adult mice (P24-P38) (Petreanu et al., 2009; Mao et al., 2011). Mice were anesthetized with isoflurane and the brain was rapidly removed and placed in cooled choline-based cutting solution (in mм: 110 choline chloride, 3.1 sodium pyruvate, 11.6 sodium ascorbate, $25 \mathrm{NaHCO}_{3}$, 25 D-glucose, $7 \mathrm{MgCl}_{2}, 2.5 \mathrm{KCl}, 1.25$ $\left.\mathrm{NaH}_{2} \mathrm{PO}_{4}, 0.5 \mathrm{CaCl}_{2}\right)$. Off-coronal sections $(300 \mu \mathrm{m})$ of vM1 were cut using a vibratome (HM 650V, Microm) (Hooks et al., 2011; Mao et al., 2011). Additional sections were cut to confirm injection location. Slices were incubated at $37^{\circ} \mathrm{C}$ in oxygenated ACSF (in mM: $127 \mathrm{NaCl}, 25$ $\mathrm{NaHCO}_{3}, 25$ D-glucose, $2.5 \mathrm{KCl}, 2 \mathrm{CaCl}_{2}, 1 \mathrm{MgCl}_{2}, 1.25 \mathrm{NaH}_{2} \mathrm{PO}_{4}$, ) for $>30 \mathrm{~min}$ and maintained at room temperature $\left(22^{\circ} \mathrm{C}\right)$ thereafter.

Whole-cell recordings were performed at $22^{\circ} \mathrm{C}$ in oxygenated ACSF with borosilicate pipettes (3-6 M $\Omega$; Warner Instruments) containing potassium gluconate-based internal solution (in mM: 128 potassium gluconate, $4 \mathrm{MgCl}_{2}$, 10 HEPES, 1 EGTA, $4 \mathrm{Na}_{2} \mathrm{ATP}, 0.4 \mathrm{Na}_{2} \mathrm{GTP}, 10$ sodium phosphocreatine, 3 sodium L-ascorbate; $\mathrm{pH} 7.27 ; 287 \mathrm{mOsm})$. In some experiments, dyes were added to the intracellular solution $(3 \mathrm{mg} / \mathrm{ml}$ biocytin or neurobiotin; $20 \mu \mathrm{M}$ Alexa-594). For subcellular ChR2assisted circuit mapping (sCRACM) experiments, TTX (1 $\mu \mathrm{M}$, Tocris Bioscience), 4-AP (100 $\mu \mathrm{M}$, Sigma), and CPP (5 $\mu \mathrm{M}$, Tocris Bioscience) were added to the bath (Petreanu et al., 2009). 4-AP blocks $\mathrm{K}^{+}$channels that are critical for repolarizing the axon. Under these conditions, short laser pulses (1-2 ms) depolarized ChR2-expressing axons in the vicinity of the laser beam and triggered the local release of glutamate. NMDA receptors were blocked (CPP) to sharpen excitatory postsynaptic responses and to prevent NMDA receptor-dependent nonlinearities in dendrites. Measurements of postsynaptic currents then revealed the presence of functional synapses between ChR2-expressing axons and the recorded neuron in the vicinity $(<60 \mu \mathrm{m})$ of the photostimulus (Petreanu et al., 2009). Blocking action potentials (TTX) also prevented contributions from polysynaptic pathways.

Data were acquired at $10 \mathrm{kHz}$ using an Axopatch 700B (Molecular Devices) and Ephus software (www.ephus.org) (Suter et al., 2010) on a custom-built laser-scanning photostimulation microscope (Shepherd et al., 2003). During sCRACM mapping, neurons were held at $-70 \mathrm{mV}$. A blue laser (473 nm, CrystaLaser) was controlled via scan mirrors (Cambridge Technology). Light pulses were controlled with a shutter (4 ms open time) in series with a Pockels cell ( $1 \mathrm{~ms}$ pulse) to deliver $0.7-1.8 \mathrm{~mW}$ at the specimen plane through a low-power objective $(4 \times, 0.16 \mathrm{NA}$, UPlanApo; Olympus). Each sweep consisted of $100 \mathrm{~ms}$ baseline and 300 $\mathrm{ms}$ following onset of the stimulus. The mapping grid $(12 \times 26$ sites, 50 $\mu \mathrm{m}$ spacing) was centered horizontally over the apical dendrite of the recorded neuron, aligned at its upper edge to the pial surface, and covered the entire dendritic arbor. Maps were repeated 2-4 times and averaged across trials. In one series of experiments (Fig. 2), we used laser-scanning photostimulation (LSPS) with glutamate uncaging, as previously described (Shepherd et al., 2003; Hooks et al., 2011).

Data analysis. Data analysis was performed with custom routines written in Matlab. Electrophysiology data were low pass filtered offline (1 $\mathrm{kHz}$ ) and synaptic events were detected using a threshold (within $23 \mathrm{~ms}$ of the stimulus with a threshold of $>6 \times$ SD from baseline). Mean EPSC for sCRACM was computed over a $75 \mathrm{~ms}$ poststimulus time window (given in $\mathrm{pA}$ ). Total input was computed by summing the suprathreshold pixels. Additional related analyses using the sum of only perisomatic pixels or the peak current in the map were performed and yielded the same results (data not shown). Paired comparisons across cells use the nonparametric Wilcoxon signed-rank test. The rank-sum test was used for nonpaired comparisons. Mean ratio of excitation were calculated as geometric means (see Figs. 5C, 6E, 7E, 9E, 12E) and the bar graph overlaid represents the mean and SD computed from 10,000 replicates of a bootstrap resampling of the ratios for each comparison. When converting an input map to an input vector for the purpose of plotting input as a function of laminar depth (see Figs. $6 F-G, 7 F-G, 9 F-G, 12 F-G$ ), we corrected for the curvature of cortex by assigning each point in the stimulus grid a normalized laminar depth [see the study by Hooks et al., 2011, 'Connectivity matrix analysis' and Fig. 6].

For anatomical experiments, we quantified the fluorescence in given target regions (see Fig. 11) and corrected for background. Because background fluorescence varied with anatomical structures, the cutoff for background value used was the mode value of the fluorescence histogram for that anatomical region. We computed total fluorescence by summation of background-subtracted pixel values and presented this as a fraction of the total (see Fig. 11G,I). To reveal densely targeted smaller structures, such as thalamus, we also normalized for each region's area; this was presented as normalized output density, using a major target (vS1 for M1 output; vM1 for M2 output) for comparison (see Fig. $11 \mathrm{H}, J)$.

\section{Results}

Paucity of local-circuit input to deeper-layer neurons in vM1 We divided vM1 into layers based on cytoarchitectonic criteria (Hooks et al., 2011), with L5A identified by a light band in bright- 

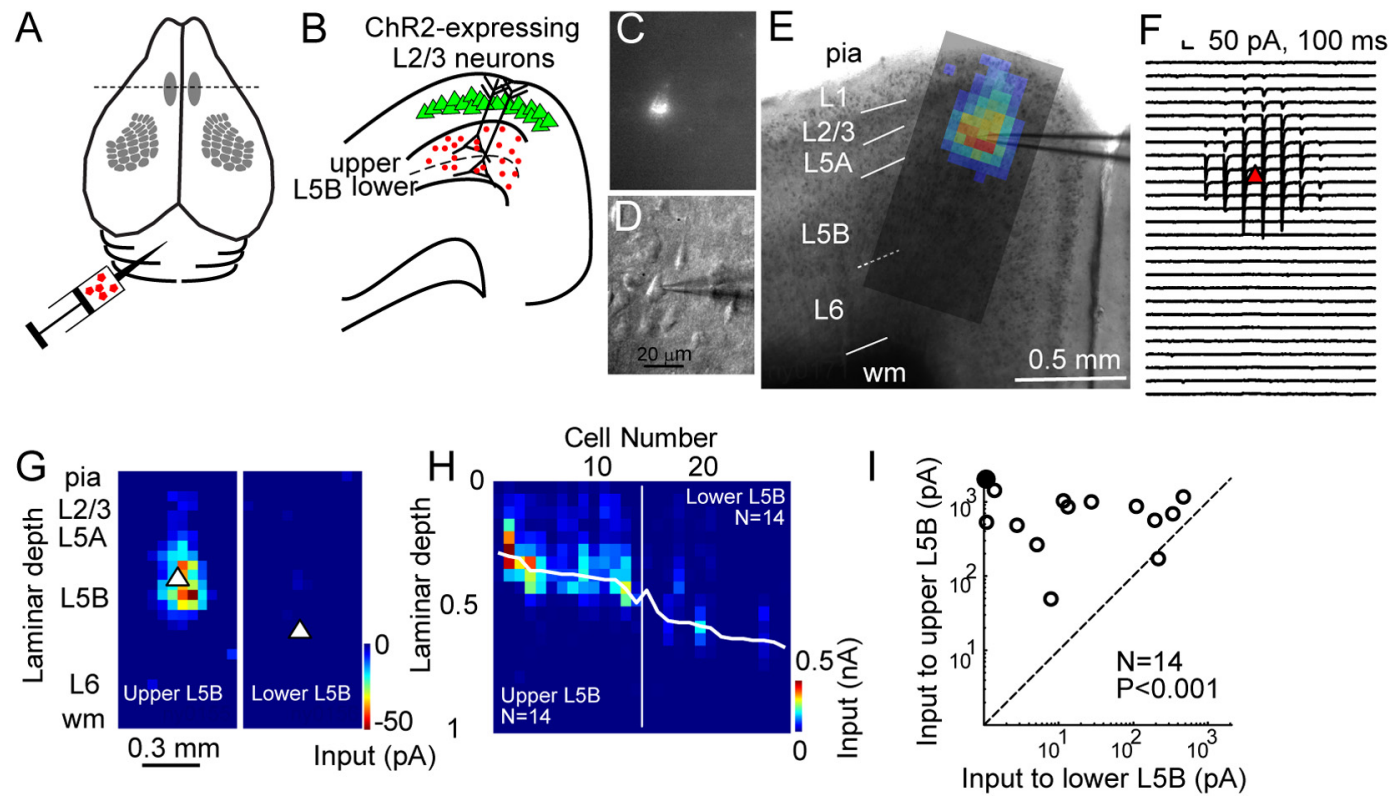

Figure 1. SCRACM reveals a lack of $L 2 / 3$ inputs to PT-type neurons in the deeper half of $L 5 B$ vibrissal motor cortex. $A$, Schematic depicting injection of retrograde tracer into pons to label PT-type neurons, in an animal previously treated with in utero electroporation of ChR2-mVenus into $L 2 / 3$ pyramidal neurons. $B$, Schematic of experiment comparing upper and lower $L 5 B$ neurons. Red dots represent retrogradely labeled PT-type neurons. Green triangles represent ChR2-expressing L2/3 pyramidal neurons. C, D, Fluorescence $(\boldsymbol{C})$ and brightfield $(\boldsymbol{D})$ images illustrating selection and patching of a retrogradely labeled PT-type neuron. E, Example sCRACM map superimposed on a brightfield image of a vM1 brain slice. Recordings were made in $1 \mu \mathrm{M}$ TTX, $100 \mu \mathrm{m} 4-\mathrm{AP}$, and $5 \mu \mathrm{M}$ CPP. Responses were measured following an $\sim 1 \mathrm{~mW}, 1 \mathrm{~ms}$ blue $(473 \mathrm{~nm}$ ) laser flash, with the laser scanned in a grid pattern ( $50 \mu \mathrm{m}$ spacing, $12 \times 26)$. $\boldsymbol{F}$, Averaged responses from three maps displayed on the grid corresponding to the blue light stimulus location (red triangle, location of the soma). G, Example sCRACM input maps for PT-type neurons in upper L5B (left) and lower L5B (right). $\boldsymbol{H}$, Input maps for L5B PT-type neurons sorted by cortical depth. Each column represents a single neuron, with its map compressed to a vector by summing across map locations at the same laminar depth, using absolute magnitude of input. The thick white line represents laminar depths of the somata. The vertical white line, demarcating the approximate mid-point of $L 5 B(0.65 \mathrm{~mm}$ from the pia), separates upper and lower L5B neurons. I, Scatter plots comparing input between upper and lower L5B neurons. Each point represents a pair of neurons in the same slice (solid circles along the axis represent neuron pairs in which one cell had no detectable input). Input represents the sum of the mean value of all suprathreshold pixels in pA. Dashed line represents equal input. Number of pairs, $N=14$ and $p$ value, $p<0.001$ (Wilcoxon signed rank test).

A
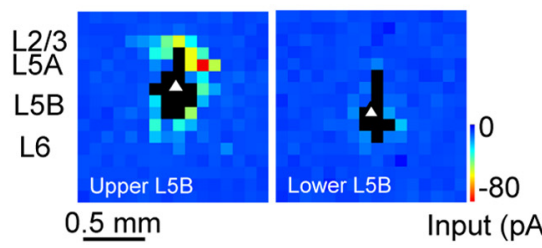

B

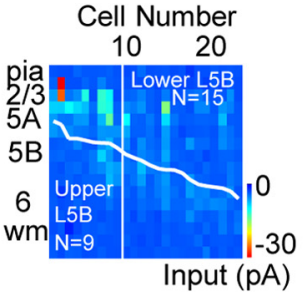

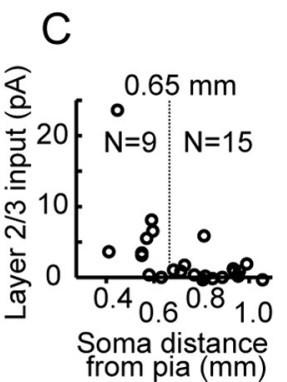

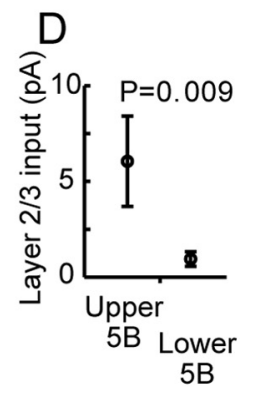

Figure 2. Laser-scanning photostimulation with glutamate uncaging confirms a lack of local-circuit inputs to deep layer PT-type neurons in vibrissal motor cortex. $A$, Example LSPS input maps for upper (left) and lower (right) L5B corticopontine (PT-type) neurons. Pixels indicate mean synaptic current; black pixels indicate direct responses. Triangles indicate somata. Pia is at the top; midline is to the right. Stimulus grid: $16 \times 16 ; 100 \mu \mathrm{m}$ spacing. $\boldsymbol{B}$, Input maps for pyramidal neurons were averaged over rows and ordered according to depth. White line indicates soma depth. Laminar depth noted at left. C, L2/3 input summed for each neuron and presented as a function of cortical depth. L5B neurons were divided into upper (blue) and lower (red) categories based on distance from pia $(0.40-0.65 \mathrm{~mm}$ upper and $0.65-1.1 \mathrm{~mm}$ lower). $\boldsymbol{D}$, Comparison of average input for lower and upper L5B neurons ( $p=0.009$, rank sum test).

field images of coronal sections. L2/3 neurons were in a relatively thin band between L1 (a light band devoid of pyramidal neurons) and L5A. L5B was darker than L5A, and distinguished from L6 by the presence of large pyramidal neurons. Laminar boundaries changed gradually with distance to the midline flexure, where L5B and L6 are expanded and L2/3 and L5A are compressed. Individual layers contain pyramidal neurons with distinct projections patterns (Peters and Jones, 1984; Molyneaux et al., 2007) and laminar molecular markers (Hooks et al., 2011). IT-type neurons (cortex/striatum projections) are located in multiple layers (L2/3, L5A, L5B, and L6), whereas PT-type neurons (brainstem/spinal cord projections) are located exclusively in L5B. CTtype neurons (defined as projecting exclusively to thalamus, including the reticular nucleus) reside in L6. Previous studies have revealed strong excitatory projections from $\mathrm{L} 2 / 3$ to neurons at the L5A/5B border, which largely avoid neurons in the deeper part of L5B and L6 (Weiler et al., 2008; Yu et al., 2008; Anderson et al., 2010; Hooks et al., 2011). Long-range input from vS1 selectively targets superficial neurons in vM1 and also avoids L5B and L6 neurons (Kaneko et al., 1994; Mao et al., 2011). The sources of input to many of the deep layer output neurons, including PT and CT type, therefore are unaccounted for by the known local and long-range cortical circuits.

Because our previous local circuit mapping in vM1 did not distinguish between PT type and other neurons in L5B, we measured input from L2/3 onto PT-type neurons using subcellular 

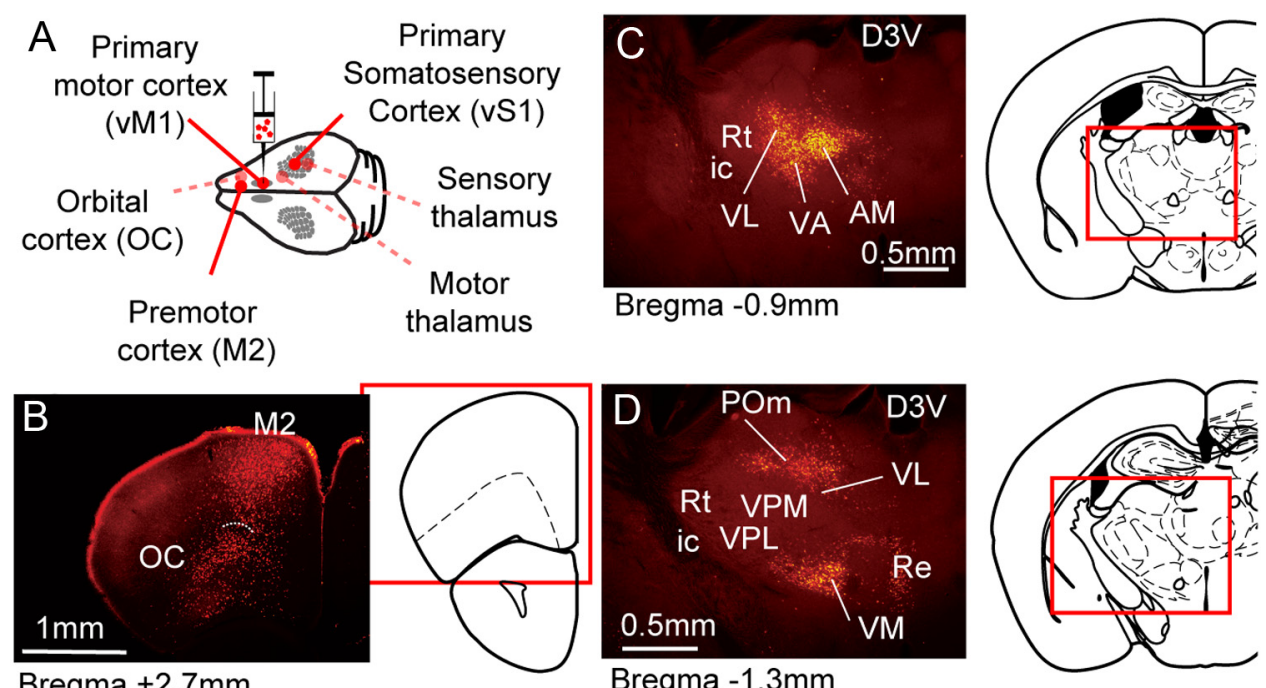

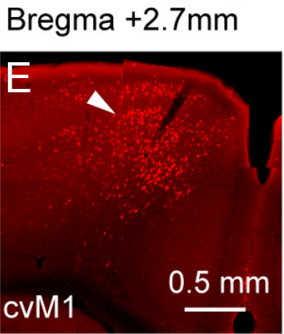

Bregma +1.0

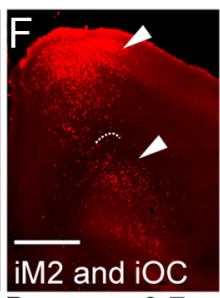

Bregma +2.7

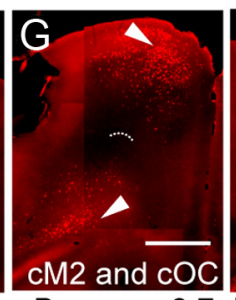

Bregma +2.7
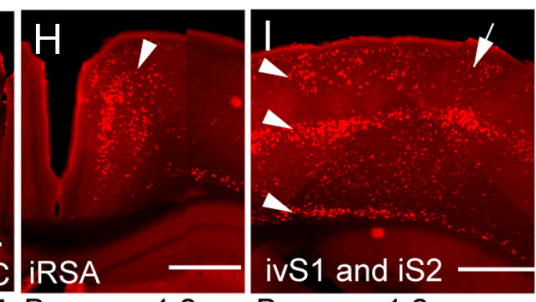

Bregma -1.2

Figure 3. Anatomical identification of long-range projections to motor cortex. $A$, Schematic of experimental design. Fluorescent retrograde tracers were stereotactically injected into mouse vM1. Relative location of five major ipsilateral cortical and thalamic afferent inputs to vM1 are shown, with deep structures indicated by dashed lines. $\boldsymbol{B}-\boldsymbol{D}$, Fluorescence images (left) of retrograde bead labeling in $100 \mu \mathrm{m}$ coronal sections (M2 and $O C, B)$ and thalamus ( $(-D)$. Position along rostrocaudal axis is indicated relative to bregma. Dashed line indicates approximate position of white matter. Abbreviations and schematics after Paxinos and Franklin (2004). D3V, Dorsal third ventricle; ic, internal capsule; Re, reuniens thalamic nucleus; Rt, reticular thalamic nucleus; VM, ventromedial thalamic nucleus; VPL, ventral posterolateral thalamic nucleus; VPM, ventral posteromedial thalamic nucleus. $E-I$, Assessment of presynaptic laminar origin of corticocortical inputs to vM1. Retrogradely labeled neurons in each presynaptic region are shown, with arrowhead indicating laminae with densest label in contralateral vM1 $(\boldsymbol{E})$, ipsilateral $M 2$ and $0 C(\boldsymbol{F}), \boldsymbol{C o n t r a l a t e r a l ~} \mathrm{M} 2$ and $O C(G)$, ipsilateral retrosplenial agranular cortex (RSA, $\boldsymbol{H}$ ), and ipsilateral vS1 and S2 (I). Arrow indicates border of vS1 (left) and S2 (right). Dashed line indicates approximate position of white matter. Scale bar, $0.5 \mathrm{~mm}$ in all panels.

channel rhodopsin-assisted circuit mapping (sCRACM) (Petreanu et al., 2009). In utero electroporation (IUEP) at embryonic day (E) 16 was used to express ChR2 tagged with Venus in L2/3 pyramidal neurons (Petreanu et al., 2007). Later, at P21-P22, we injected retrograde fluorescent tracers into the pontine nuclei in vivo to label PT-type neurons (Fig. $1 A, B$ ). We then assessed L2/3 input to upper and lower L5B PT-type pyramidal neurons in brain slices (Fig. $1 B-F$ ). Because ChR2 expression level varies among IUEP mice, pairs of PT-type neurons at different depths in L5B, aligned on the same radial axis (lateral distance $<200$ $\mu \mathrm{m})$, were recorded sequentially in the same brain slice and compared. Photostimuli were delivered on a grid pattern covering the entire dendritic arbor of the recorded cell (Fig. 1E-G). EPSCs (Fig. $1 F$ ), averaged over multiple repetitions, were used to generate mean pixel values in sCRACM input maps (Fig. $1 G$ ). The resulting input maps of each PT-type neuron were reduced to single vectors and presented as a function of laminar depth (Fig. $1 \mathrm{H}$ ). The strength of input for a given neuron was calculated as the sum over all pixels with detectable input $(>6 \mathrm{SD}$; alternative analysis using the sum of only perisomatic pixels or the peak current in the map showed the same results, data not shown). $\mathrm{L} 2 / 3$ input to PT-type neurons was strong in upper L5B, and much weaker in lower L5B ( $>20$-fold difference, $p<0.001$; Fig. 1I).

In a complementary set of experiments, we used glutamate uncaging and laser-scanning photostimulation (glu-LSPS) (Cal- laway and Katz, 1993; Schubert et al., 2001; Shepherd et al., 2003; Hooks et al., 2011) to map excitatory inputs to retrogradely labeled PT-type neurons in vM1. Potential presynaptic neurons were excited by focal glutamate uncaging while recording from a postsynaptic neuron, and the process was repeated for many stimulus locations to generate maps of synaptic input. Input maps confirmed the paucity of descending excitatory input to PT-type neurons in lower L5B (Fig. 2). Thus, PT-type neurons in lower $\mathrm{L} 5 \mathrm{~B}$ receive weak interlaminar excitation from pyramidal neurons in the local circuit and little long-range input from vS1 (Mao et al., 2011). These observations motivated us to search for other long-range excitatory inputs to L5B and L6 of vM1.

\section{Identification of long-range inputs to vM1}

We identified brain regions projecting to vM1 by injecting fluorescent retrograde tracers into vM1 (Fig. 3). Multiple cortical and thalamic regions were labeled, including ipsilateral primary and secondary somatosensory cortices ( $\mathrm{vS} 1$ and S2), secondary motor cortex (M2), orbital cortex (OC), and anterior and posterior thalamic nuclei (including AM, VA, VL, and POm). With the exception of $\mathrm{vM} 1$, contralateral projections were weak. In cortical areas, we also examined the laminar distributions of retrograde labeling. Inputs to $\mathrm{vM} 1$ predominantly came from the superficial layers of ipsilateral M2 and contralateral M1 and M2. Ipsilateral vS1 and S2 inputs originated in L2/3, L5A, with a minor contribution from deeper layer neurons (Mao et al., 2011). OC inputs 

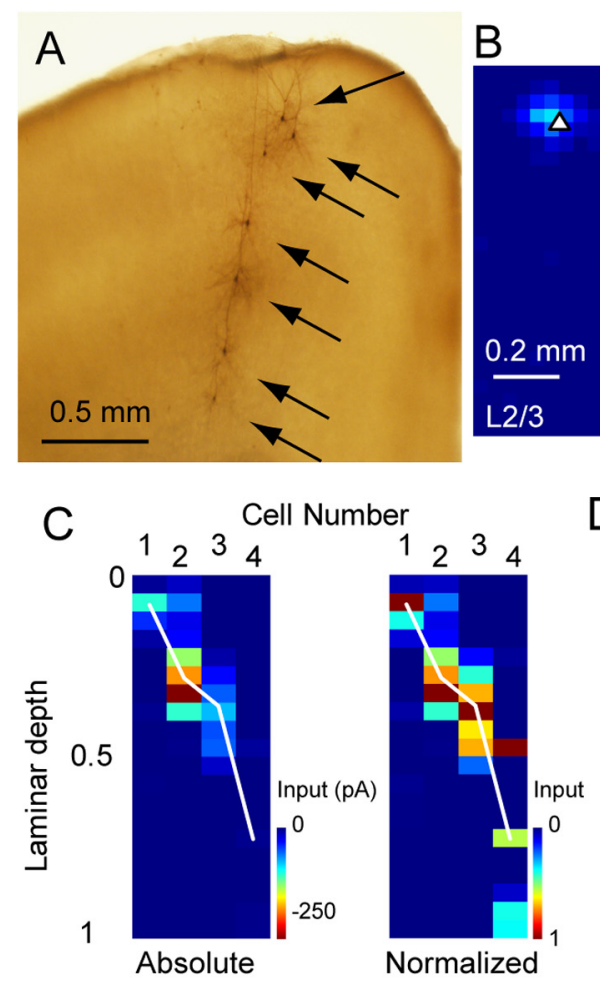

B

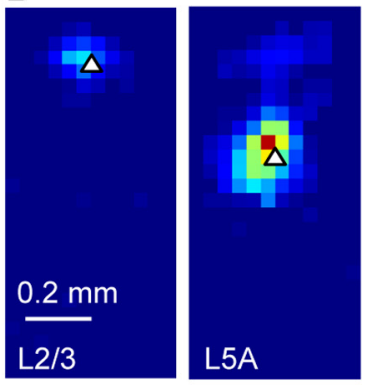

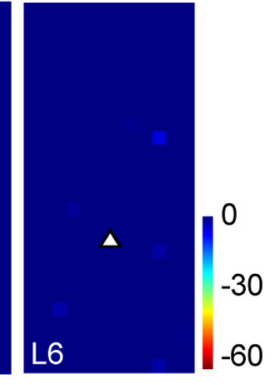

Input (pA)

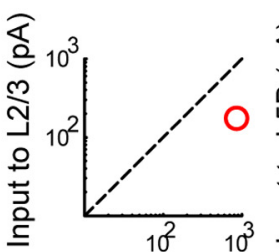

Input to L5A (pA)

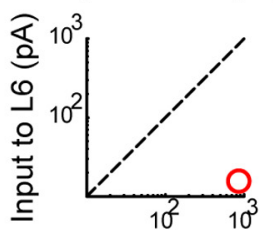

Input to L5A (pA)

Figure 4. Comparing input strength from a single pathway across layers using SCRACM. $A-D$, Illustration showing how inputs to neurons in different cortical layers were compared. $\boldsymbol{A}$, Multiple pyramidal neurons were recorded in the same neocortical column and filled with biocytin. $\boldsymbol{B}$, Mean current during $75 \mathrm{~ms}$ poststimulus is represented as a heat map with the same scale (at right) for four cells from the same slice in (from left to right) L2/3, L5A, L5B, and L6. Neuronal somata indicated by triangles. $C$, Each column represents a single neuron, with the input map of $B$ reduced to a vector by summing input across map locations at the same laminar depth. The white line overlaid represents laminar depth of the cell body. Red pixels represent locations of maximum input. The absolute plot (left) uses the sum of the measured currents and plots all neurons on the same scale. The normalized plot (right) scales the vector for each neuron from 0 (blue, minimum input) to 1 (red, maximum input) to show location of input in the arbor. $\boldsymbol{D}$, lllustration of input strength comparison. The sum of all suprathreshold pixels in a map is compared for neurons recorded in different layers of the same slice. Sum of input is given in pA and plotted on a logarithmic plot. Dashed line represents unity. L5A is used to compare with other layers for posterior thalamus, as it was the layer with strongest average inputs.

showed a distinct pattern of laminar origin, with denser labeling in deeper layers in ipsilateral OC, but more superficial labeling in contralateral OC.

We selected the strongest ipsilateral inputs to vM1 for further investigation: thalamus, M2, and OC. Functional inputs from vS1 to vM1 have been studied previously (Mao et al., 2011). We refer to the dorsal anterior frontal cortex as M2; this area has also been referred to as frontal association cortex (Paxinos and Franklin, 2004), among other terms (Brecht, 2011). Our definition of $\mathrm{M} 2$ as a region anterior to vM1 differs from the Paxinos atlas definition, in which M2 also extends posteriorly, medial to (somatic) M1. This region, however, corresponds to vM1 as identified by microstimulation, anatomical connection to vS1, and retrograde labeling from the whisker pad with pseudorabies virus (Brecht et al., 2004; Hooks et al., 2011). Our designation of M2 is consistent with the way in which premotor areas in the primate have been operationally defined on the basis of directly projecting to M1 (Muakkassa and Strick, 1979; Dum and Strick, 2005).

\section{Excitatory inputs from sensory thalamus to vM1}

We used sCRACM to study inputs to pyramidal neurons in all layers of vM1. AAV was used to express ChR2 tagged with fluorescent proteins (ChR2-XFP) (Mao et al., 2011) one brain region at a time. After 2-4 weeks of expression, we recorded input to vM1 pyramidal neurons. Multiple neurons, aligned along the radial axis (lateral separation $<200 \mu \mathrm{m}$ ) were recorded and filled with biocytin (Fig. 4A). The maps of neurons in multiple layers from the same slice were then compared to assess the relative strengths of input to different types of pyramidal neurons (Fig. $4 B-D)$.

AAV injections into different thalamic areas produced two distinct patterns of axonal density. Because these areas do not segregate into distinct sets of annotated nuclei we call these areas "motor thalamus" and "sensory thalamus." Sensory thalamic injections encompassed POm and the posterior portions of VL. Similarly, motor thalamic injections encompassed AM, VA, and anterior parts of VL. Grouping injections based on the anterior/ posterior coordinates of injection site gave similar results as that based on projection pattern (Fig. 5). Individual infection volumes (375-600 $\mu$ m radius) typically included more than one thalamic nucleus, but smaller injection volumes did not result in sufficient ChR2 expression to perform CRACM experiments. Thus, it was not possible to assess whether the projection differences between the two thalamic pathways were due to a specific nucleus.

Sensory thalamus projected strongly to vM1 (Fig. 3). Expression of ChR2-XFP in sensory thalamus ( $N=21$ mice, P26-P35; Fig. $6 \mathrm{~A}$ ) resulted in bright bands of axonal fluorescence in $\mathrm{L} 1$ and L5A (Fig. $6 B, C$ ). Comparing the input across multiple sets of neurons in different slices revealed that the input to L5A neurons was $\sim 8$ times stronger than to L5B neurons $(p<0.001)$ and $>50$ times stronger than to L6 neurons ( $p=0.031)$; input to L2/3 


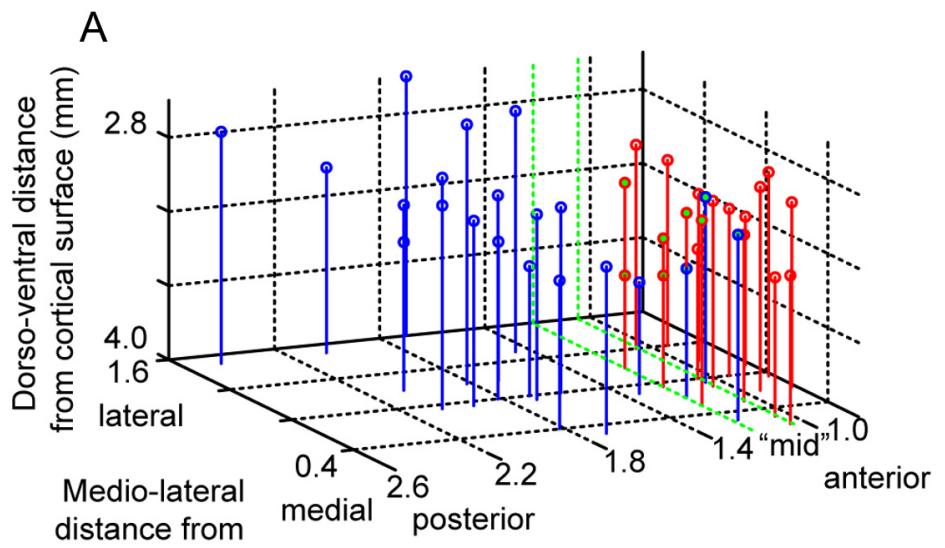
midline $(\mathrm{mm})$
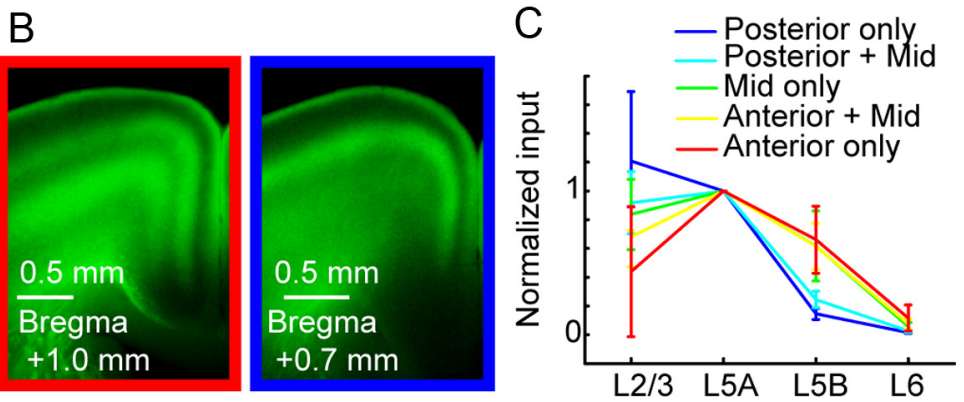

Figure 5. Analysis of motor cortex input from thalamus, grouped by injection site location. $A$, Thalamic injection coordinates were estimated based on sections containing strong AAV expression and dye coinjection with virus. Coordinates (in $\mathrm{mm}$ ) are given in depth from the surface of cortex, distance from the midline, and anterior/posterior position relative to bregma (Paxinos and Franklin, 2004). Motor thalamus (red) and sensory thalamus (blue) overlapped in a region ( 1-1.2 mm posterior to bregma), designated as "mid" (green). B, Example images of axon pattern in cortex from anterior (left) and posterior (right) injections. This pattern was used to categorize injections into sensory and motor thalamic categories. C, Geometric means of the intensity ratio, normalized to the layer receiving the strongest input (LSA). The overlaid graph shows the mean ratio and SD (bootstrap, see Materials and Methods). In posterior injections (blue), L5B input was low, but L5B input strength increased in data groupings including mid (green) and anterior injection sites (red).

neurons was comparable to L5A neurons (Fig. 6D,E). The laminar pattern of input from the sensory thalamus was indistinguishable to that from vS1 (Mao et al., 2011). Specific targeting of $\mathrm{L} 2 / 3$ and L5A neurons is apparent in un-normalized input maps (Fig. 6F, left).

The normalized input maps highlight the subcellular distributions of inputs across the dendrites of the recorded neurons (Fig. $6 F, G) . \mathrm{L} 2 / 3$ and L5A neurons receive mainly perisomatic input, with a center of mass just below the soma. Thalamic input to L1 of L2/3 and L5A neurons were present but less prominent, at least in part due to electrotonic attenuation (Fig. 6G).

\section{Excitatory inputs from motor thalamus to vM1}

Motor thalamus also projects strongly to vM1 (Fig. 3). Expression of ChR2-XFP in motor thalamus ( $N=20$ mice, P27-P36; Fig. $7 A$ ) produced three bands of fluorescent axons in L1 (only within a superficial sublayer), L5A, and L5B (Fig. $7 \mathrm{~B}, \mathrm{C}$ ). Neurons in $\mathrm{L} 2 / 3$, L5A, and $\mathrm{L} 5 \mathrm{~B}$ received strong input from motor thalamus, whereas L6 received significantly less input (Fig. $7 D, E, p=$ 0.016). This input preference was also evident in the unnormalized analysis (Fig. 7F, left). L2/3 input diminished as thalamic injections moved from posterior to anterior (Fig. $5 C$ ). Excitatory inputs to L5A were generally perisomatic, although L1 input was evident. In contrast, L2/3 neurons received motor thalamic inputs to two regions: basal dendrites below the soma, and apical dendrites in L1, with the latter more prominent than in posterior thalamic injections (Fig. 7G).

Since motor thalamus excited L5B pyramidal cells, which may include PT-type neurons, we investigated whether inputs occur in a projection-specific manner. We labeled PT-type neurons by injecting retrograde tracer into the pontine nuclei and recorded from labeled and unlabeled neighboring L5B neurons. Labeled and unlabeled neurons received similar levels of input from motor thalamus (Fig. $8 A, B$, $p=0.922)$. Therefore, we conclude that all L5B pyramidal cell types, including PTtype neurons, receive strong input from motor thalamic axons. We further compared the strength of input received by upper and lower L5B neurons (Fig. 8C,D), and again found no significant differences, thus indicating that anterior thalamic afferents do not discriminate between sublayers of L5B neurons in vM1.

\section{Excitatory inputs from M2 to vM1}

We next studied input from the $\mathrm{M} 2$ region of frontal cortex $(2.7 \mathrm{~mm}$ anterior to bregma and $0.9 \mathrm{~mm}$ lateral), an area strongly labeled by injection of retrograde tracer into vM1. Projections from M2 originated predominantly from neurons in the upper layers of cortex (Fig. 3). Expression of ChR2-XFP in M2 $(N=25$ mice, P24-P32; Fig. 9A) resulted in an axonal fluorescence pattern that was approximately complementary to that measured from sensory thalamus and vS1. Fluorescent bands of axonal labeling were seen in deep layers, predominantly L5B and L6 (Fig. 9 B, C). Consistent with the laminar input pattern, L5B pyramidal neurons received larger input than either L2/3 $(p=0.002)$ or L5A $(p<$ $0.001)$ neurons. L6 neurons received relatively higher M2 input than L2/3 and L5A, but also significantly less than L5B neurons $(p=0.020$; Fig. 9D,E). These patterns were also seen in the un-normalized maps (Fig. 9F, left). M2 input tended to be perisomatic (Fig. 9G). As with motor thalamic injections, labeled L5B PT-type neurons and unlabeled L5B neurons at similar laminar depth received quantitatively similar input (Fig. 10 A,B). Because the axonal fluorescence from M2 increases with depth across $\mathrm{L} 5 \mathrm{~B}$, we hypothesized that deeper $\mathrm{L} 5 \mathrm{~B}$ neurons may receive stronger input from M2. Comparison of upper and lower L5B neurons in the same slices revealed significantly greater excitation to the deeper half of L5B ( $p=0.019$; Fig. $10 C, D)$.

\section{Comparison of vM1 and M2 at the level of outputs and inputs} vM1 and M2 are cytoarchitectonically similar areas, with no clear anatomical demarcation. We directly compared these areas by mapping their outputs and inputs using anterograde labeling with AAV-GFP and retrograde labeling with fluorescent tracers (Fig. 11). Both areas were strongly interconnected with other frontal areas, including ipsilateral and contralateral OC, M2, and vM1 (Figs. $11 A, B, D-F, 8 J-M)$. Projections to thalamus were 

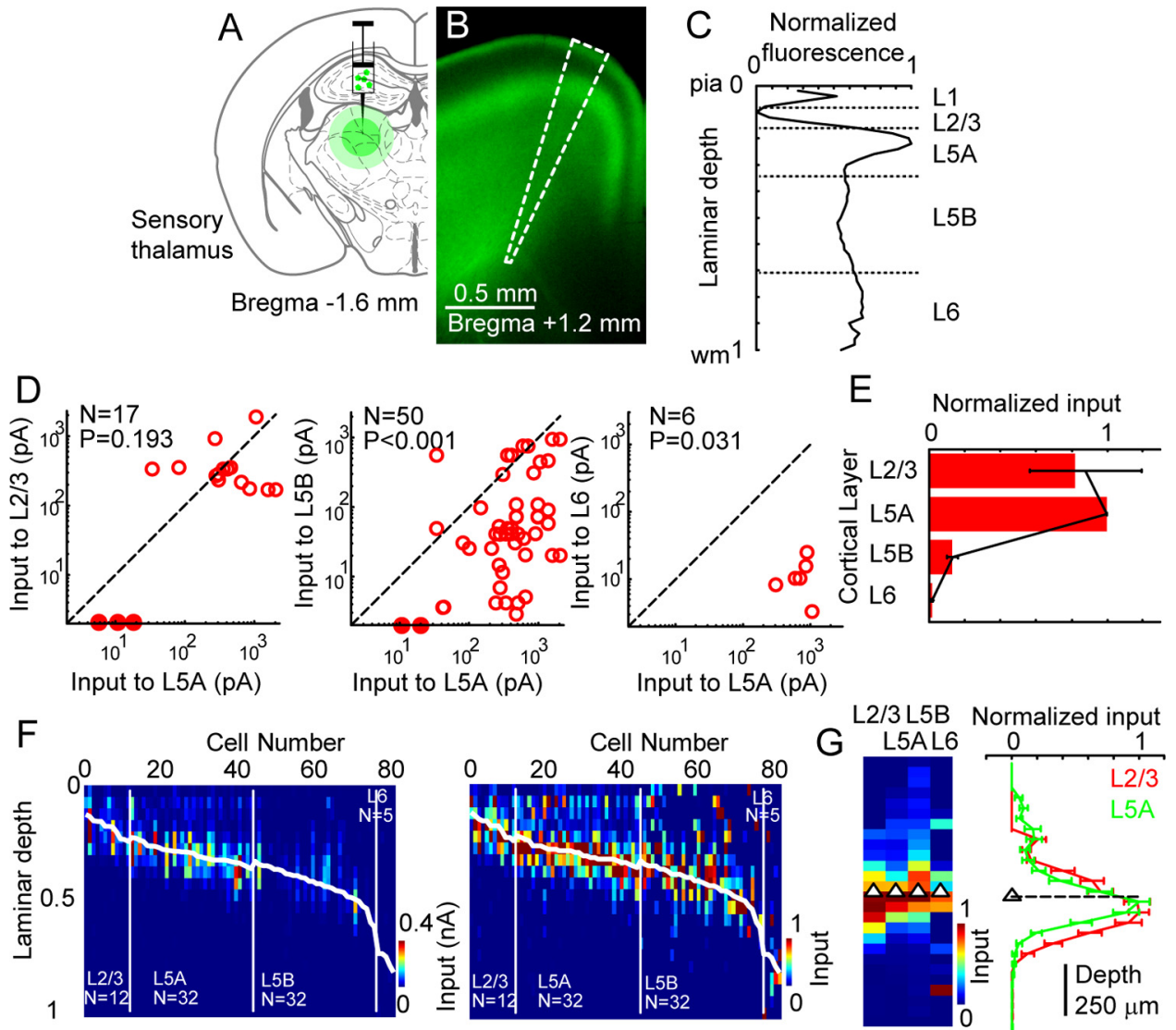

Figure 6. Inputs to vM1 from sensory thalamus. $A, A A V$ injection site in posterior thalamus, after Paxinos and Franklin (2004). $B$, Fluorescence image of a coronal vM1 section (thickness, $300 \mu \mathrm{m}$ ) showing axonal fluorescence. Dashed lines mark region used for fluorescence quantification. C, Quantification of fluorescence as a function of laminar depth. Cortical depth is shown in fractional coordinates (pia, 0 ; white matter, 1); fluorescence was background subtracted and normalized. Dashed lines indicate borders of cortical layers. Note peaks in L1 and L5A, as well as the plateau near white matter. $\boldsymbol{D}$, Comparison of input strength across neurons in different cortical layers. Each point represents input to a pair of neurons in the same slice (solid circles, neuron pairs in which one cell had no detectable input). Dashed line represents unity. N, Number of pairs; $p$ value, Wilcoxon signed rank test. $\boldsymbol{E}$, Geometric means of the amplitude ratio, normalized to the layer receiving the strongest input (L5A). The overlaid graph shows the mean ratio and SD (bootstrap). $F$, Left, input maps for pyramidal neurons grouped by layer. Each column represents a single neuron, with its map compressed to a vector by summing across map locations at the same laminar depth. Thick white line, Laminar depth of the cell body. Vertical white lines, Boundaries separating layers. Color map adjusted to saturate top $0.5 \%$ of pixels. Right, Same neurons presented with input for each cell normalized its maximum input. G, Description of input location for pyramidal neurons for all four layers. Normalized mean input maps for each pyramidal neuron layer were averaged into a vector and aligned to the soma. These were then plotted as an input vector (left) and a graph (right), showing the input as a function of laminar depth relative to the soma in $50 \mu \mathrm{m}$ bins. Triangles and dashed lines indicate soma depth. Only the strongest recipient layers (L2/3 and L5A) are plotted at right. Note points above the pia are plotted as zero.

partially overlapping, with M2 targets shifted medially (Fig. $11 C, F)$.

\section{Excitatory inputs from OC to vM1}

We next investigated input from the OC, including lateral (LO) and ventral (VO) regions of Paxinos and Franklin (2004). Neurons in deep layers of ipsilateral OC were strongly labeled by injection of retrograde tracer into vM1 (Fig. 3). Due to the orientation of OC, here the shallowest layers are ventral. Expression of ChR2-XFP in OC ( $N=11$ mice, P26-P38; Fig. 12A) produced bands of fluorescent axons in deep layers. Fluorescence was brightest in L6 and tapered in shallower layers more rapidly than in $\mathrm{M} 2$ injections (Fig. $12 \mathrm{~B}, \mathrm{C}$ ). Although pyramidal neurons in all layers received detectable input, this was limited to $20-30 \%$ that of L6 neurons (Fig. 12 D, E; L6 vs L2/3, $p=0.001$; L6 vs L5A, $p=$ 0.003 ; L6 vs L5B, $p=0.002$ ). L6 input preference was also evident in the un-normalized analysis (Fig. $12 \mathrm{~F}$, left). As in the M2 projection, these afferents formed predominantly perisomatic contacts (Fig. 12G). These results establish a second type of corticocortical input pathway that preferentially targets the deep- est layers of vM1. The laminar distribution of excitatory input from all pathways is shown in Figure 13A.

\section{Discussion}

Different long-range inputs to vM1 excited pyramidal neurons in distinct laminar patterns. Each source targeted only a subset of vM1 layers. Collectively, cortical and thalamic inputs partially interdigitated and overlapped across layers, accounting for excitation to all layers (Fig. 13). Sensory thalamus targeted superficial layers (L2/3 and L5A) in a pattern indistinguishable from vS1 inputs (Mao et al., 2011). Motor thalamus targeted these layers but also excited L5B, including PT-type neurons. M2 mainly targeted deep layers of vM1, especially L5B, including PT-type neurons. OC targeted L6, which includes CT-type neurons. Our studies reveal prominent long-range input to subcerebral output neurons in vM1, the excitatory inputs to which were previously unidentified. This circuit organization suggests that frontal cortex areas directly control motor areas in the brainstem and the spinal cord via M1 output neurons. 
A

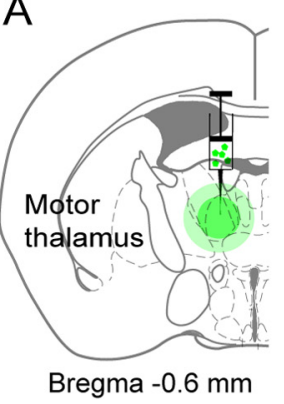

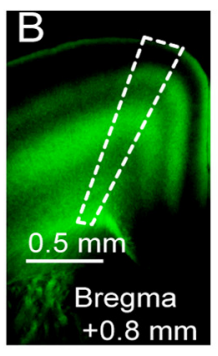

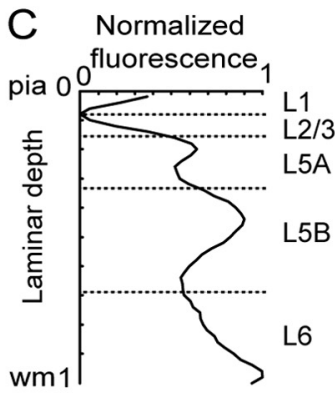

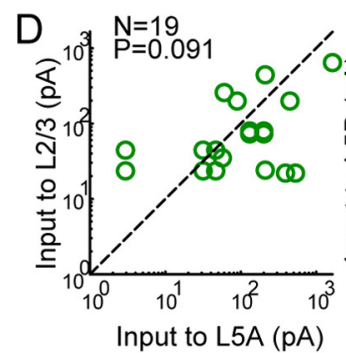
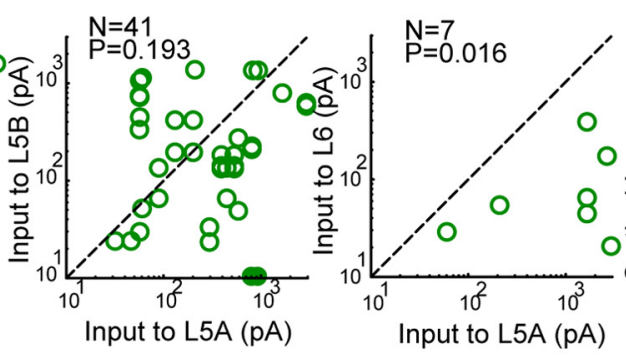

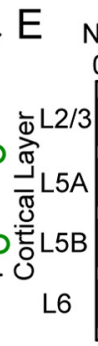

Normalized input
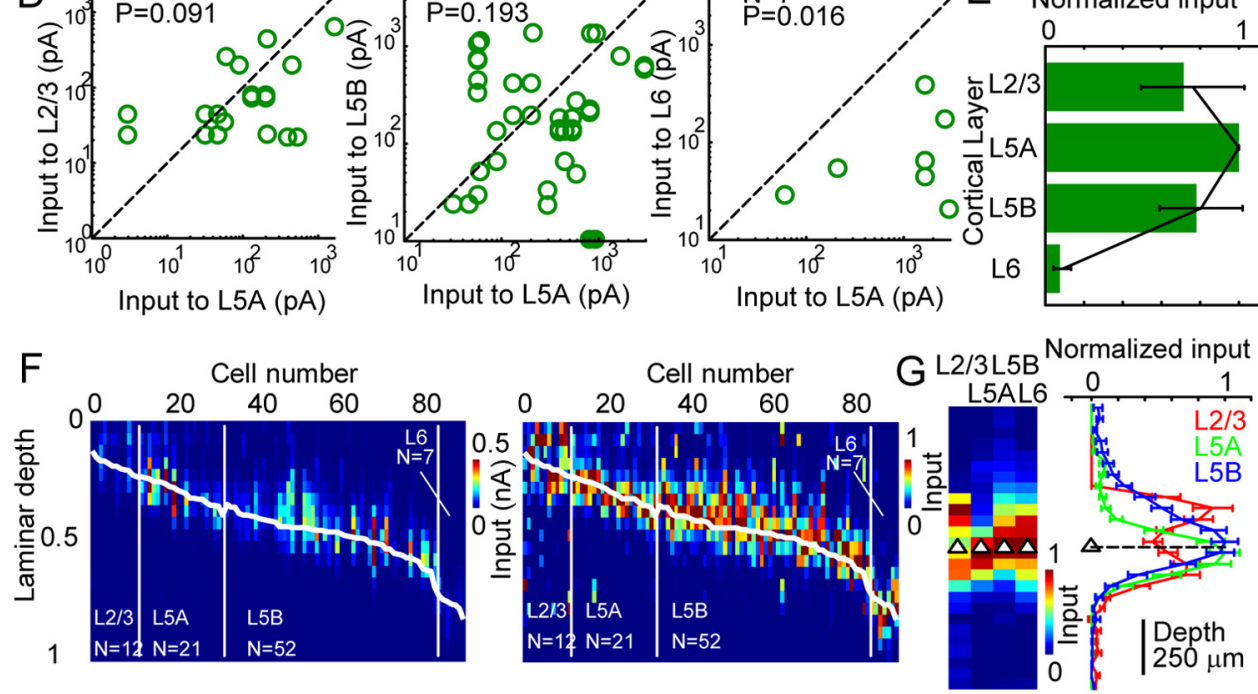

Figure 7. Inputs to vM1 from motor thalamus. A, AAV injection site in anterior thalamus, after Paxinos and Franklin (2004). B, Fluorescence image of a coronal vM1 section (thickness, $300 \mu \mathrm{m}$ ) showing axonal fluorescence. Dashed lines mark region used for fluorescence quantification. C, Quantification of fluorescence as a function of laminar depth. Cortical depth is shown in fractional coordinates (pia, 0; white matter, 1); fluorescence was background subtracted and normalized. Dashed lines indicate borders of cortical layers. Note peaks in L1, L5A, and L5B, as well as a peak near white matter. $\boldsymbol{D}$, Comparison of input strength across neurons in different cortical layers. Each point represents input to a pair of neurons in the same slice (solid circles, neuron pairs in which one cell had no detectable input). Dashed line represents unity. N, Number of pairs; $p$ value, Wilcoxon signed rank test. $\boldsymbol{E}$, Geometric means of the amplitude ratio, normalized to the layer receiving the strongest input (L5A). The overlaid graph shows the mean ratio and SD (bootstrap). $F$, Left, input maps for pyramidal neurons grouped by layer. Each column represents a single neuron, with its map compressed to a vector by summing across map locations at the same laminar depth. Thick white line, Laminar depth of the cell body. Vertical white lines, Boundaries separating layers. Color map adjusted to saturate top $0.5 \%$ of pixels. Right, Same neurons presented with input for each cell normalized its maximum input. G, Description of input location for pyramidal neurons for all four layers. Normalized mean input maps for each pyramidal neuron layer were averaged into a vector and aligned to the soma. These were then plotted as an input vector (left) and a graph (right), showing the input as a function of laminar depth relative to the soma in $50 \mu \mathrm{m}$ bins. Triangles and dashed lines indicate soma depth. Only the strongest recipient layers $(L 2 / 3, L 5 A$, and $L 5 B)$ are plotted at right. Note points above the pia are plotted as zero.
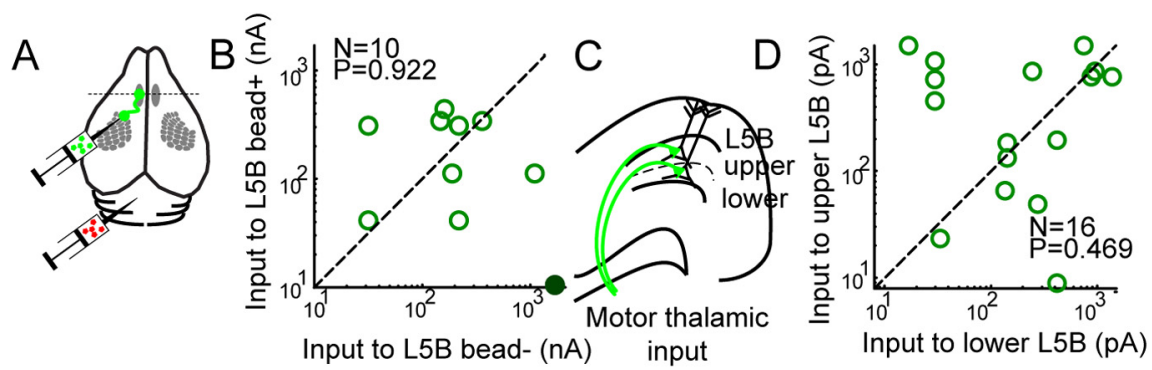

Figure 8. Input from motor thalamus to subtypes of $L 5 B$ neurons in vM1.A, Schematic illustrating injection of ChR2-expressing AAV (green) into anterior thalamus and retrograde tracer (red) into pontine nuclei to label PT-type neurons. B, Comparison of input strength between retrogradely labeled PT-type pyramidal neurons and their unlabeled neighbors. Each point represents input to a pair of neurons in the same slice (solid circles, neuron pairs in which one cell had no detectable input). Dashed line represents unity. N, Number of pairs; $p$ value, Wilcoxon signed rank test. Differences not significant. C, Schematic of experiment comparing upper and lower neurons in L5B to explore sublaminar differences. $\mathrm{L} 5 \mathrm{~B}$ neurons recorded in the same slice were divided into upper (laminar depth 0.35-0.51) and lower (laminar depth 0.52-0.67) groups and input compared as before. Green arrows represent motor thalamic input to each class. $\boldsymbol{D}$, Comparison of input strength between upper and lower $L 5 B$ neurons. Each point represents input to a pair of neurons in the same slice. Dashed line represents unity. N, Number of pairs; $p$ value, Wilcoxon signed rank test. Differences not significant.
Subcellular ChR2-assisted circuit mapping

sCRACM (Petreanu et al., 2009) measures the strength and subcellular targeting of monosynaptic connections between ChR2-expressing presynaptic axons and postsynaptic dendrites. Inputs were defined by stereotaxic viral injection, and postsynaptic neurons were defined by the laminar locations of the somata and, in some cases, retrograde labeling. The strength of evoked synaptic input depends on ChR2 expression level, which varies across experiments. We therefore recorded from multiple neurons per slice and normalized to determine the laminar profile of excitatory input. Our method relies on somatic whole-cell recording, which underestimates the strength of electrotonically distant inputs (Petreanu et 

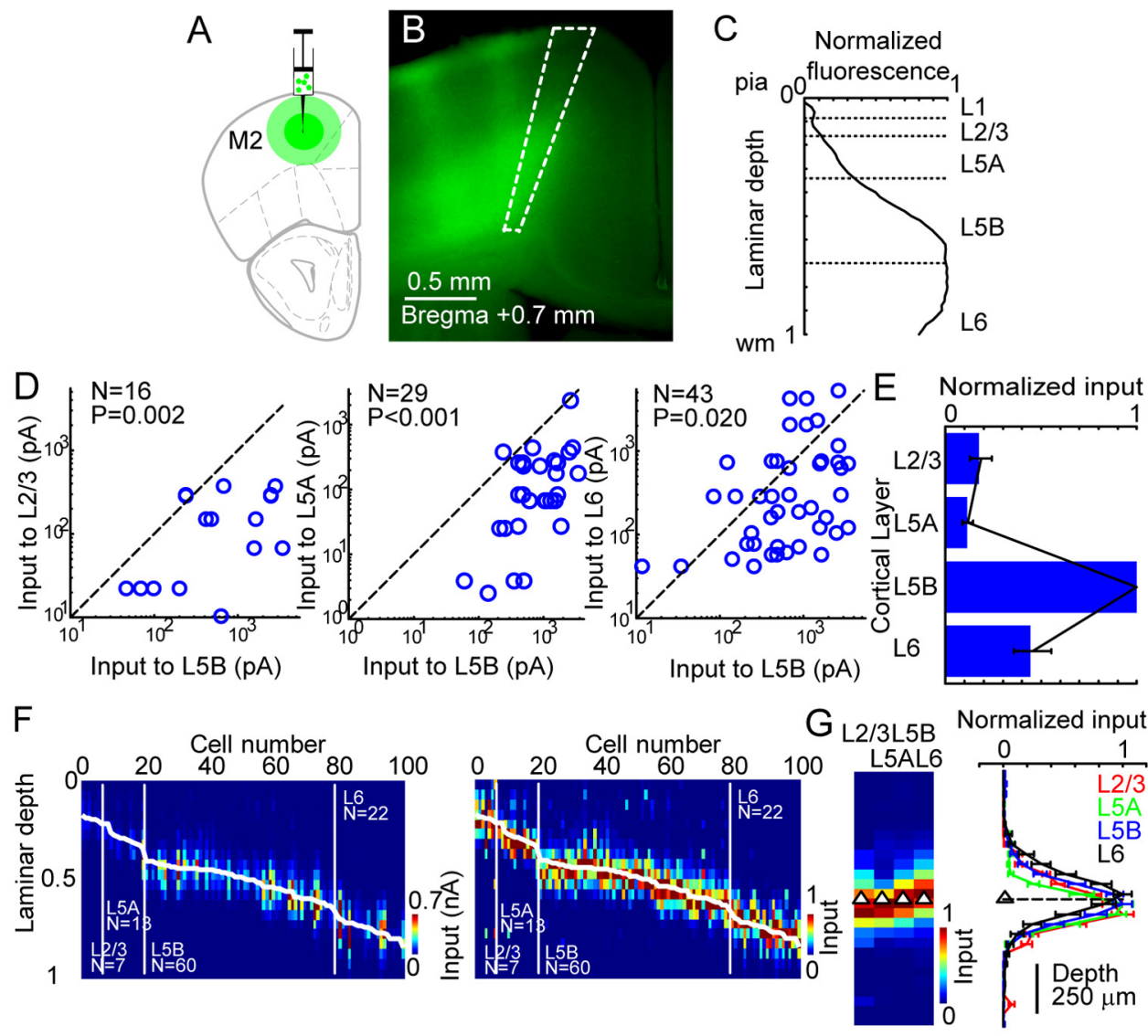

Figure 9. Frontal cortex (M2) excites the output layers of vM1. A-G, Quantification of inputs to vM1 from M2. A, AAV injection site in M2, after Paxinos and Franklin (2004). $\boldsymbol{B}$, Fluorescence image of a coronal vM1 section (thickness, $300 \mu \mathrm{m}$ ) showing axonal fluorescence. Dashed lines mark region used for fluorescence quantification. $\mathbf{C}$, Quantification of fluorescence as a function of laminar depth. Cortical depth is shown in fractional coordinates (pia, 0; white matter, 1); fluorescence was background subtracted and normalized. Dashed lines indicate borders of cortical layers. Note a single peak in deep layers (L5B and L6). D, Comparison of input strength across neurons in different cortical layers. Each point represents input to a pair of neurons in the same slice. Dashed line represents unity. $N$, Number of pairs; $p$ value, Wilcoxon signed rank test. $E$, Geometric means of the amplitude ratio, normalized to the layer receiving the strongest input (L5B). The overlaid graph shows the mean ratio and SD (bootstrap). $F$, Left, Input maps for pyramidal neurons grouped by layer. Each column represents a single neuron, with its map compressed to a vector by summing across map locations at the same laminar depth. Thick white line, Laminar depth of the cell body. Vertical white lines, Boundaries separating layers. Color map adjusted to saturate top $0.5 \%$ of pixels. Right, Same neurons presented with input for each cell normalized its maximum input. $\mathbf{G}$, Description of input location for pyramidal neurons for all four layers. Normalized mean input maps for each pyramidal neuron layer were averaged into a vector and aligned to the soma. These were then plotted as an input vector (left) and a graph (right), showing the input as a function of laminar depth relative to the soma in $50 \mu \mathrm{m}$ bins. Triangles and dashed lines indicate soma depth. Note points above the pia are plotted as zero.

al., 2009). We could not assess short-term synaptic plasticity, which may modulate the strength of different inputs, perhaps in an input-specific manner. Furthermore, our experiments focused on only monosynaptic excitatory connectivity in longrange projections. Additional studies will be needed to address how inhibitory interneurons are incorporated into the excitatory circuits described here.

Inputs to superficial layers arise primarily from sensory-related areas Projections from the sensory thalamus (POm and posterior VL) excited pyramidal cells in superficial layers of vM1, L2/3, and L5A (Fig. 6), similar to vS1 inputs (Mao et al., 2011). Thus, vM1 receives ascending sensory information directly via POm and the paralemniscal pathway and indirectly via vS1 (Diamond et al., 1992;
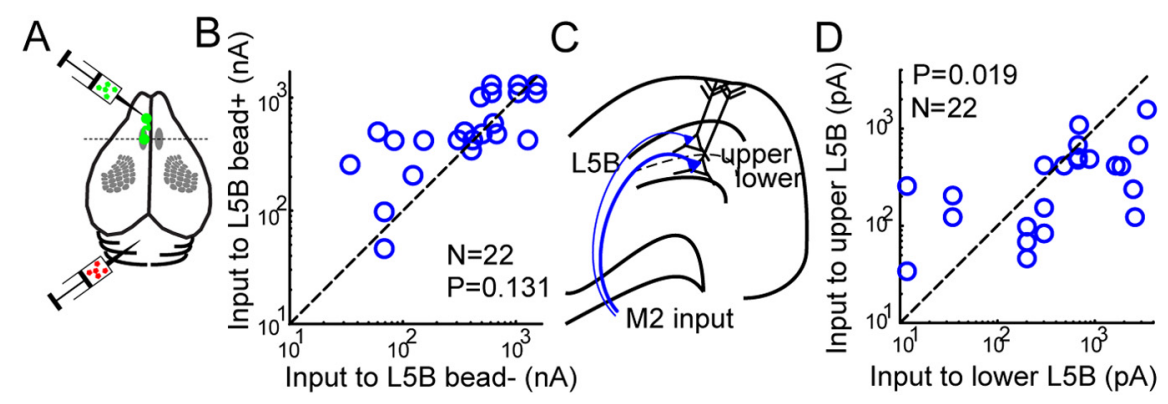

Figure 10. Input from $M 2$ to subtypes of $L 5 B$ neurons in vM1. A, Schematic illustrating injection of ChR2-expressing AAV (green) into M2 and retrograde label (red) into pontine nuclei to label PT-type neurons. $\boldsymbol{B}$, Comparison of input strength between retrogradely labeled PT-type pyramidal neurons and their unlabeled neighbors. Each point represents input to a pair of neurons in the same slice. Dashed line represents unity. $N$, Number of pairs; $p$ value, Wilcoxon signed rank test. Differences not significant. C, Schematic of experiment comparing upper and lower neurons in L5B to explore sublaminar differences. L5B neurons recorded in the same slice were divided into upper (laminar depth $0.35-0.51$ ) and lower (laminar depth $0.52-0.67)$ groups and input compared as before. Blue arrows represent differences in M2 input to each class. $\boldsymbol{D}$, Comparison of input strength between upper and lower $L 5 B$ neurons. Each point represents input to a pair of neurons in the same slice. Dashed line represents unity. $N$, Number of pairs; $p$ value, Wilcoxon signed rank test. Lower L5B neurons received more input $(p=0.019)$. 

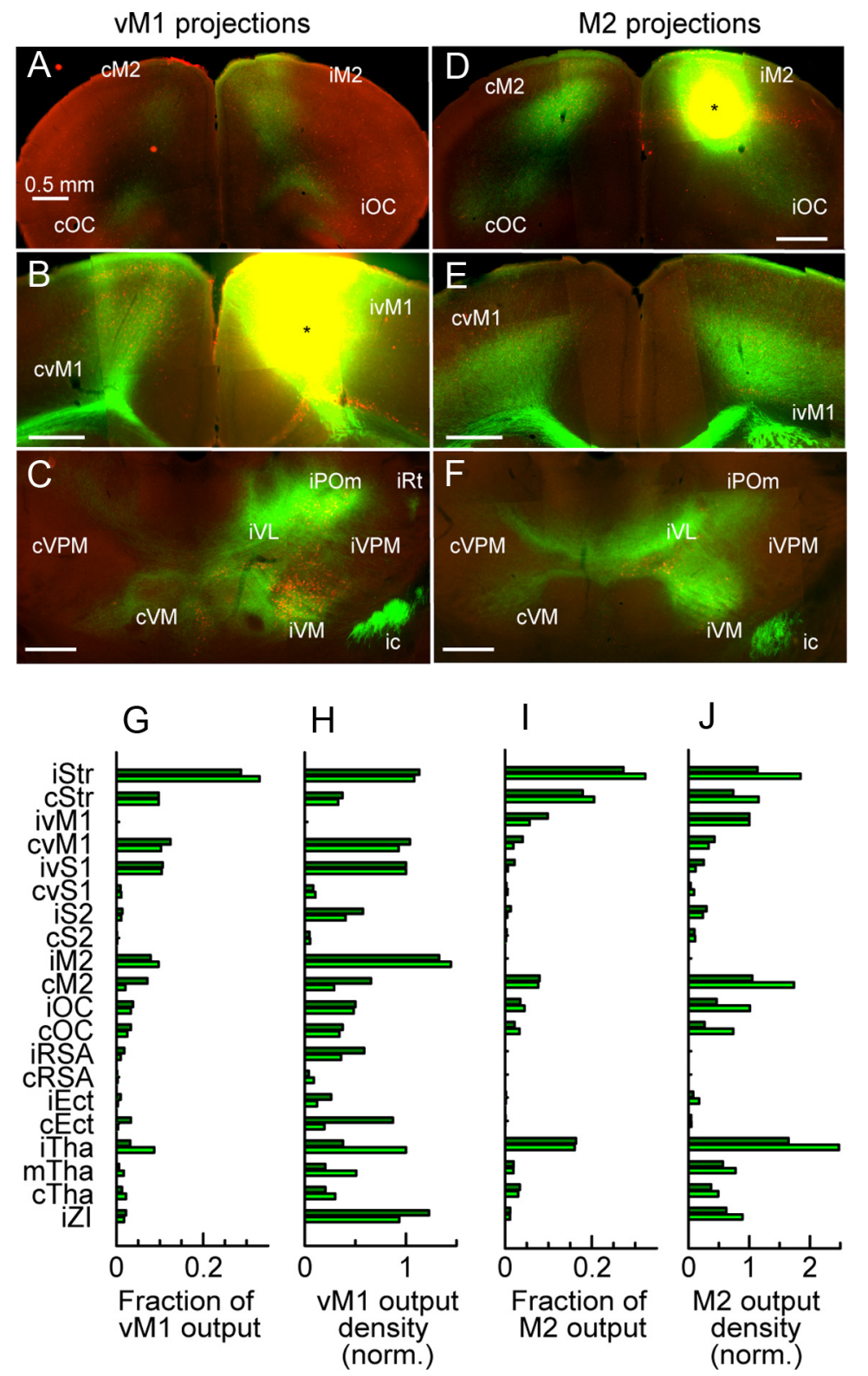

Figure 11. Analysis of $\mathrm{vM} 1$ and $\mathrm{M} 2$ long-range projections. $\boldsymbol{A}-\boldsymbol{F}$, Coinjection of AAV-EGFP and retrograde tracer in vM1 or $M 2$ in adult mice. After $>2$ weeks of expression, animals were sectioned in $100 \mu \mathrm{m}$ coronal sections and imaged with a fluorescence microscope (Axiolmager). Prefixes "i", "m", and " $c$ " designate ipsilateral, medial, and contralateral, respectively. $\boldsymbol{A}-\boldsymbol{C}, \mathrm{vM} 1$ injection shows reciprocal connections with $\mathrm{M} 2,0 \mathrm{C}(\boldsymbol{A})$, contralateral vM1 $(\boldsymbol{B})$, and thalamus $(\boldsymbol{C}) . \boldsymbol{D}-\boldsymbol{F}, \mathrm{M} 2$ injection also reveals reciprocal connections with vM1 $(\boldsymbol{E}), 0 C$, contralateral $M 2(\boldsymbol{E})$, and thalamus with a medial shift relative to vM1 projections $(\boldsymbol{F}) . \boldsymbol{G}$, Quantification of the total fluorescence of from vM1 injections (sum of pixels) across targets in the cortex, basal ganglia, and thalamus for $N=2$ animals. Thalamic nuclei are grouped into ipsilateral (iTha), contralateral (cTha), and midline (mTha; for unpaired nuclei) thalamic nuclei. Prefixes "i", "m", and " $c$ " designate ipsilateral, medial, and contralateral, respectively. Ect, Ectorhinal cortex; Str, striatum; Zl, zona incerta. $\boldsymbol{H}$, Output density for vM1 injections, where fluorescence is divided by area and divided by output density to vS1 for normalization. I, J, Quantification of total fluorescence and output density for M2 injections $(N=2$ animals) in a similar fashion. vM1 is used for normalization in $J$.

Sherman, 2007). Excitatory input also enters M1 from deep cerebellar nuclei and basal ganglia via VA/VL (Hoover and Strick, 1999). Sensory-related activity has been recorded in the superficial layers of cat (Porter et al., 1990) and rodent M1 (Ferezou et al., 2007; Murray and Keller, 2011; Huber et al., 2012). Inputs from S1 and sensory thalamus interact at the level of single superficial neurons (Iriki et al., 1989). We therefore suggest that L2/3 and L5A, which project locally to upper L5B, may be especially important for sensorimotor processing; that is, these circuits may subserve movements guided by sensory stimuli.
Inputs to deeper layers arise primarily from frontal areas

Pyramidal neurons in lower layers received little input from sensory thalamus (Fig. 6), and previous studies have shown that they also receive little input from either local vM1 neurons (Hooks et al., 2011) or vS1 (Mao et al., 2011). Our results confirm previous anatomical results showing that M2 and OC project to M1 (Reep et al., 1990; Rouiller et al., 1993), and extend those studies by identifying L5B and L6 neurons as the cellular targets of excitatory synaptic input from these areas. Specifically, axons from M2 targeted lower L5B and also provided significant input to L6 (Fig. 9), and axons from OC targeted predominantly L6 alone (Fig. 12). Our survey of projections to vM1 (Fig. 3) suggests that these brain regions provide most of corticocortical input to these neurons, although we cannot rule out the possibility that other projections provide strong synaptic inputs despite being numerically weak. Retrogradely labeled neurons in M2 were mainly in the superficial layers, consistent with observations in primate cortex (Lu et al., 1994). The deeper-layer targeting of inputs from frontal cortical areas is complimentary to the upper-layer targeting of inputs from S1 and posterior (sensory) thalamus. The connectivity of PT-type neurons in lower L5B and CT-type neurons in L6 suggests that their activity could be substantially influenced by inputs from frontal cortical areas. The innervation of L6 neurons by OC axons furthermore suggests a specialized role for OC in regulating corticothalamic feedback; for example, OC may exert executive control over M1dependent actions through these direct connections to L6 neurons. Because M2 and OC inputs directly innervate PT-type and CT-type neurons, frontomotor signals bypass local circuit input and act directly to influence excitatory output to brainstem and thalamus. M1 thus may operate in different modes depending on the behavioral task. Consistent with this idea, superficial and deep layers of primate temporal cortex are differentially recruited in a context-dependent manner (Takeuchi et al., 2011).

\section{Inputs from the motor thalamus}

Our results extend previous anatomical descriptions (Herkenham, 1980) of the projection from motor thalamus to M1, showing that these inputs target pyramidal neurons in both the superficial layers of vM1 and also in L5B (Fig. 7). Tracing of single thalamocortical neurons has indicated distinct projection patterns from rostromedial and caudolateral zones in the motor thalamus (Kuramoto et al., 2009). These anatomical projection patterns do not easily corre- 

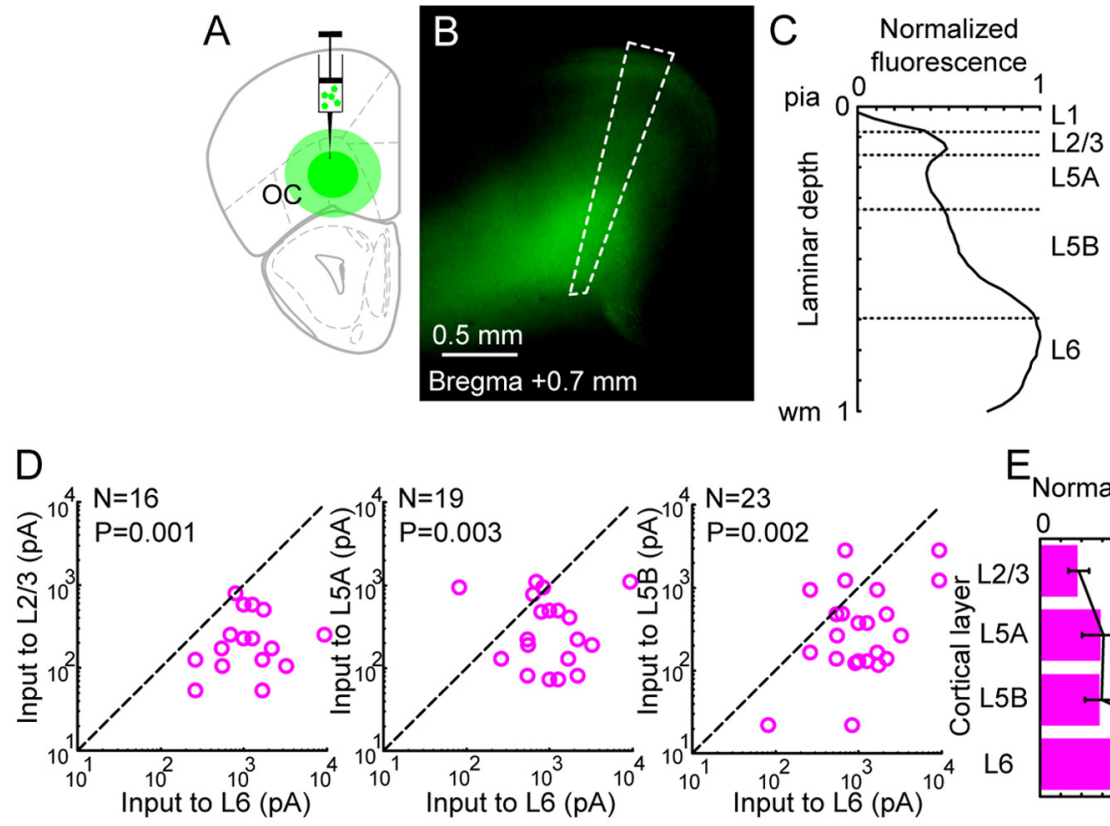

$\mathrm{E}_{\mathrm{N}}$
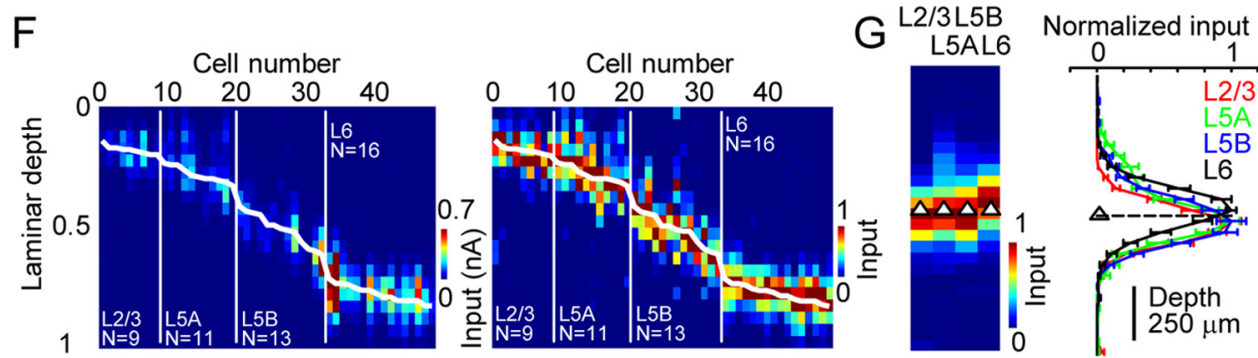

Figure 12. $O C$ excites $L 6$ neurons in vM1. A, AAV injection site in $O C$, after Paxinos and Franklin (2004). B, Fluorescence image of a coronal vM1 section (thickness, $300 \mu \mathrm{m}$ ) showing axonal fluorescence. Dashed lines mark region used for fluorescence quantification. C, Quantification of fluorescence as a function of laminar depth. Cortical depth is shown in fractional coordinates (pia, 0; white matter, 1); fluorescence was background subtracted and normalized. Dashed lines indicate borders of cortical layers. Note peaks in L2/3 and near the L5B/L6 border. $D$, Comparison of input strength across neurons in different cortical layers. Each point represents input to a pair of neurons in the same slice. Dashed line represents unity. $N$, number of pairs; $p$ value, Wilcoxon signed rank test. $\boldsymbol{E}$, Geometric means of the amplitude ratio, normalized to the layer receiving the strongest input ( $(6)$ ). The overlaid graph shows the mean ratio and SD (bootstrap). $F$, Left, input maps for pyramidal neurons grouped by layer. Each column represents a single neuron, with its map compressed to a vector by summing across map locations at the same laminar depth. Thick white line, Laminar depth of the cell body. Vertical white lines, Boundaries separating layers. Color map adjusted to saturate top $0.5 \%$ of pixels. Right, Same neurons presented with input for each cell normalized its maximum input. G, Description of input location for pyramidal neurons for all four layers. Normalized mean input maps for each pyramidal neuron layer were averaged into a vector and aligned to the soma. These were then plotted as an input vector (left) and a graph (right), showing the input as a function of laminar depth relative to the soma in $50 \mu \mathrm{m}$ bins. Triangles and dashed lines indicate soma depth. Note points above the pia are plotted as zero.

spond with the three bands of axons (L1, $\mathrm{L} 2 / 3 / 5 \mathrm{~A}, 5 \mathrm{~B}$ ) produced by injections in the anterior thalamus (Fig. $7 B, C$ ), as one of the single-cell patterns preferentially targets layer 1 , and the other targets L2/3. These differences may relate to the species (mouse vs rat) or the techniques used. In cats, for example, VA/VL axons project primarily to layer 2/3 in M1, but corticospinal neurons are also innervated via synaptic contacts onto their apical dendrites (Strick and Sterling, 1974).

\section{Sublayer differentiation of L5B and PT-type projection neurons} Interestingly, PT-type neurons in upper and lower sublayers of L5B received distinct inputs. In M1 and other frontal agranular areas, L5B spans $\sim 25-30 \%$ of the cortical thickness (Caviness, 1975; Weiler et al., 2008; Hooks et al., 2011) and contains at least two sublayers based on

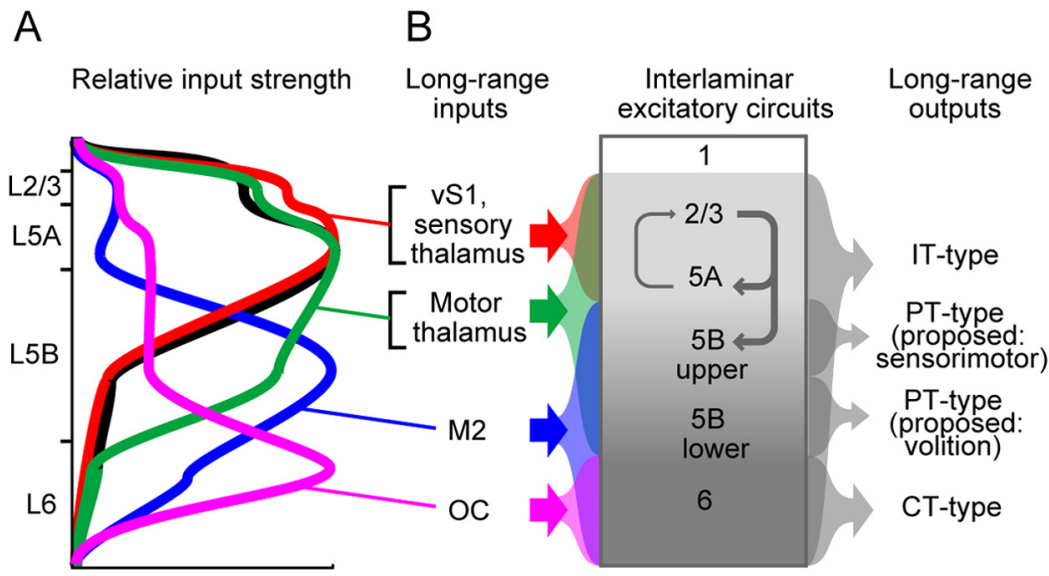

Figure 13. Circuit diagram for lamina-specific long-range excitation to primary motor cortex.A, Schematic showing the relative input strength from each pathway to layers in vM1, based on ratios measured in Figures $6,7,9$, and 12 . Profile of vS1 input (black) (Mao et al., 2011) is included for comparison. B, A circuit diagram for excitatory inputs to primary motor cortex. Left, Laminar specificity of long-range excitatory input is shown for all pathways described. Input from vS1 to vM1 is included with sensory thalamus. Center, Interlaminar excitatory circuits between vM1 pyramidal neurons (gray) are dominated by descending pathways. Right, Long-range outputs of vM1 are shown, with laminar specificity indicated. 
circuit mapping (Yu et al., 2008; Shepherd, 2009; Anderson et al., 2010). Consistent with previous studies (Weiler et al., 2008; Yu et al., 2008; Anderson et al., 2010; Hooks et al., 2011), local-circuit excitatory input from L2/3 was strongest for pyramidal neurons in upper L5B (Fig. 1). Conversely, excitatory input from M2 was strongest for pyramidal neurons in lower L5B (Fig. 10). Anterior thalamic inputs, in contrast, were similar for upper and lower L5B (Fig. 8). Certain classes of PT-type neurons, including corticospinal and corticopontine neurons, are distributed across the full thickness of L5B, implying that distinct functional subpopulations exist within these projection classes in different sublayers. Specifically, the activity of upper L5B PT-type neurons may be more influenced by upstream circuits involved in sensory processing (via local M1 L2/3 neurons), whereas lower L5B PT-type neurons may be more influenced by upstream circuits involved in more cognitive aspects of motor behavior (via M2). Conversely, other classes of PT-type neurons appear restricted to just one or more particular sublayers in L5B (Mao et al., 2011; Hirai et al., 2012), implying that entire classes may be preferentially influenced by either sensory or cognitive related systems. Our data, by providing evidence for a graded sensory/cognitive division across $\mathrm{L} 5 \mathrm{~B}$, raise the possibility that subcerebral projections are differentiated into frontomotor and sensorimotor output channels.

\section{References}

Anderson CT, Sheets PL, Kiritani T, Shepherd GMG (2010) Sublayerspecific microcircuits of corticospinal and corticostriatal neurons in motor cortex. Nat Neurosci 13:739-744. CrossRef Medline

Asanuma H (1981) Functional role of sensory inputs to the motor cortex. Prog Neurobiol 16:241-262. CrossRef Medline

Asanuma H, Larsen KD, Yumiya H (1979) Receptive fields of thalamic neurons projecting to the motor cortex in the cat. Brain Res 172:217-228. CrossRef Medline

Asanuma H, Larsen K, Yumiya H (1980) Peripheral input pathways to the monkey motor cortex. Exp Brain Res 38:349-355. Medline

Brecht M (2011) Movement, confusion, and orienting in frontal cortices. Neuron 72:193-196. CrossRef Medline

Brecht M, Krauss A, Muhammad S, Sinai-Esfahani L, Bellanca S, Margrie TW (2004) Organization of rat vibrissa motor cortex and adjacent areas according to cytoarchitectonics, microstimulation, and intracellular stimulation of identified cells. J Comp Neurol 479:360-373. CrossRef Medline

Callaway EM, Katz LC (1993) Photostimulation using caged glutamate reveals functional circuitry in living brain slices. Proc Natl Acad Sci U S A 90:7661-7665. CrossRef Medline

Caviness VS Jr (1975) Architectonic map of neocortex of the normal mouse. J Comp Neurol 164:247-263. CrossRef Medline

Cruikshank SJ, Urabe H, Nurmikko AV, Connors BW (2010) Pathwayspecific feedforward circuits between thalamus and neocortex revealed by selective optical stimulation of axons. Neuron 65:230-245. CrossRef Medline

Deschênes M, Veinante P, Zhang ZW (1998) The organization of corticothalamic projections: reciprocity versus parity. Brain Res Brain Res Rev 28:286-308. Medline

Diamond ME, Armstrong-James M, Budway MJ, Ebner FF (1992) Somatic sensory responses in the rostral sector of the posterior group (POm) and in the ventral posterior medial nucleus (VPM) of the rat thalamus: dependence on the barrel field cortex. J Comp Neurol 319:66-84. CrossRef Medline

Dum RP, Strick PL (2002) Motor areas in the frontal lobe of the primate. Physiol Behav 77:677-682. CrossRef Medline

Dum RP, Strick PL (2005) Frontal lobe inputs to the digit representations of the motor areas on the lateral surface of the hemisphere. J Neurosci 25: 1375-1386. CrossRef Medline

Ferezou I, Haiss F, Gentet LJ, Aronoff R, Weber B, Petersen CC (2007) Spatiotemporal dynamics of cortical sensorimotor integration in behaving mice. Neuron 56:907-923. CrossRef Medline

Fetz EE (1969) Operant conditioning of cortical unit activity. Science 163: 955-958. CrossRef Medline
Haggard P (2008) Human volition: towards a neuroscience of will. Nat Rev Neurosci 9:934-946. CrossRef Medline

Hatsopoulos NG, Suminski AJ (2011) Sensing with the motor cortex. Neuron 72:477-487. CrossRef Medline

Herkenham M (1980) Laminar organization of thalamic projections to the rat neocortex. Science 207:532-535. CrossRef Medline

Hill DN, Curtis JC, Moore JD, Kleinfeld D (2011) Primary motor cortex reports efferent control of vibrissa motion on multiple timescales. Neuron 72:344-356. CrossRef Medline

Hirai Y, Morishima M, Karube F, Kawaguchi Y (2012) Specialized cortical subnetworks differentially connect frontal cortex to parahippocampal areas. J Neurosci 32:1898-1913. CrossRef Medline

Hoffer ZS, Hoover JE, Alloway KD (2003) Sensorimotor corticocortical projections from rat barrel cortex have an anisotropic organization that facilitates integration of inputs from whiskers in the same row. J Comp Neurol 466:525-544. CrossRef Medline

Hooks BM, Hires SA, Zhang YX, Huber D, Petreanu L, Svoboda K, Shepherd GMG (2011) Laminar analysis of excitatory local circuits in vibrissal motor and sensory cortical areas. PLoS Biol 9:e1000572. CrossRef Medline

Hoover JE, Strick PL (1999) The organization of cerebellar and basal ganglia outputs to primary motor cortex as revealed by retrograde transneuronal transport of herpes simplex virus type 1. J Neurosci 19:1446-1463. Medline

Huber D, Gutnisky DA, Peron S, O'Connor DH, Wiegert JS, Tian L, Oertner TG, Looger LL, Svoboda K (2012) Multiple dynamic representations in the motor cortex during sensorimotor learning. Nature 484:473-478. CrossRef Medline

Iriki A, Pavlides C, Keller A, Asanuma H (1989) Long-term potentiation in the motor cortex. Science 245:1385-1387. CrossRef Medline

Jeannerod M, Frak V (1999) Mental imaging of motor activity in humans. Curr Opin Neurobiol 9:735-739. CrossRef Medline

Kaneko T, Caria MA, Asanuma H (1994) Information processing within the motor cortex. II. Intracortical connections between neurons receiving somatosensory cortical input and motor output neurons of the cortex. J Comp Neurol 345:172-184. CrossRef Medline

Kaneko T, Cho R, Li Y, Nomura S, Mizuno N (2000) Predominant information transfer from layer III pyramidal neurons to corticospinal neurons. J Comp Neurol 423:52-65. CrossRef Medline

Koralek AC, Jin X, Long JD 2nd, Costa RM, Carmena JM (2012) Corticostriatal plasticity is necessary for learning intentional neuroprosthetic skills. Nature 483:331-335. CrossRef Medline

Kuramoto E, Furuta T, Nakamura KC, Unzai T, Hioki H, Kaneko T (2009) Two types of thalamocortical projections from the motor thalamic nuclei of the rat: a single neuron-tracing study using viral vectors. Cereb Cortex 19:2065-2077. CrossRef Medline

Lu MT, Preston JB, Strick PL (1994) Interconnections between the prefrontal cortex and the premotor areas in the frontal lobe. J Comp Neurol 341:375-392. CrossRef Medline

Mao T, Kusefoglu D, Hooks BM, Huber D, Petreanu L, Svoboda K (2011) Long-range neuronal circuits underlying the interaction between sensory and motor cortex. Neuron 72:111-123. CrossRef Medline

Molyneaux BJ, Arlotta P, Menezes JR, Macklis JD (2007) Neuronal subtype specification in the cerebral cortex. Nat Rev Neurosci 8:427-437. CrossRef Medline

Muakkassa KF, Strick PL (1979) Frontal lobe inputs to primate motor cortex: evidence for four somatotopically organized 'premotor' areas. Brain Res 177:176-182. CrossRef Medline

Murray PD, Keller A (2011) Somatosensory response properties of excitatory and inhibitory neurons in rat motor cortex. J Neurophysiol 106: 1355-1362. CrossRef Medline

Nambu A, Yoshida S, Jinnai K (1988) Projection on the motor cortex of thalamic neurons with pallidal input in the monkey. Exp Brain Res 71: 658-662. CrossRef Medline

Ohno S, Kuramoto E, Furuta T, Hioki H, Tanaka YR, Fujiyama F, Sonomura T, Uemura M, Sugiyama K, Kaneko T (2012) A morphological analysis of thalamocortical axon fibers of rat posterior thalamic nuclei: a single neuron tracing study with viral vectors. Cereb Cortex 22:2840-2857. CrossRef Medline

Paxinos G, Franklin HBJ (2004) The mouse brain in stereotaxic coordinates: compact second edition. Amsterdam: Elsevier.

Peters A, Jones EG (1984) Classification of cortical neurons. In: Cellular 
components of the cerebral cortex (Jones EG, Peters A, eds), pp 361-380. New York: Plenum.

Petreanu L, Huber D, Sobczyk A, Svoboda K (2007) Channelrhodopsin-2assisted circuit mapping of long-range callosal projections. Nat Neurosci 10:663-668. CrossRef Medline

Petreanu L, Mao T, Sternson SM, Svoboda K (2009) The subcellular organization of neocortical excitatory connections. Nature 457:1142-1145. CrossRef Medline

Petreanu L, Gutnisky DA, Huber D, Xu NL, O'Connor DH, Tian L, Looger L, Svoboda K (2012) Activity in motor-sensory projections reveals distributed coding in somatosensation. Nature 489:299-303. CrossRef Medline

Porro CA, Francescato MP, Cettolo V, Diamond ME, Baraldi P, Zuiani C, Bazzocchi M, di Prampero PE (1996) Primary motor and sensory cortex activation during motor performance and motor imagery: a functional magnetic resonance imaging study. J Neurosci 16:7688-7698. Medline

Porter LL, Sakamoto T, Asanuma H (1990) Morphological and physiological identification of neurons in the cat motor cortex which receive direct input from the somatic sensory cortex. Exp Brain Res 80:209-212. Medline

Reep RL, Goodwin GS, Corwin JV (1990) Topographic organization in the corticocortical connections of medial agranular cortex in rats. J Comp Neurol 294:262-280. CrossRef Medline

Rokni U, Richardson AG, Bizzi E, Seung HS (2007) Motor learning with unstable neural representations. Neuron 54:653-666. CrossRef Medline

Rouiller EM, Moret V, Liang F (1993) Comparison of the connectional properties of the two forelimb areas of the rat sensorimotor cortex: support for the presence of a premotor or supplementary motor cortical area. Somatosens Mot Res 10:269-289. CrossRef Medline

Schieber MH (2011) Dissociating motor cortex from the motor. J Physiol 589:5613-5624. CrossRef Medline

Schubert D, Staiger JF, Cho N, Kötter R, Zilles K, Luhmann HJ (2001) Layer-specific intracolumnar and transcolumnar functional connectivity of layer V pyramidal cells in rat barrel cortex. J Neurosci 21:3580-3592. Medline

Shepherd GMG (2009) Intracortical cartography in an agranular area. Front Neurosci 3:337-343. CrossRef Medline

Shepherd GMG, Pologruto TA, Svoboda K (2003) Circuit analysis of experience-dependent plasticity in the developing rat barrel cortex. Neuron 38:277-289. CrossRef Medline

Sherman SM (2007) The thalamus is more than just a relay. Curr Opin Neurobiol 17:417-422. CrossRef Medline

Smith NJ, Horst NK, Liu B, Caetano MS, Laubach M (2010) Reversible inactivation of rat premotor cortex impairs temporal preparation, but not inhibitory control, during simple reaction-time performance. Front Integr Neurosci 4:124. Medline

Strick PL, Sterling P (1974) Synaptic termination of afferents from the ventrolateral nucleus of the thalamus in the cat motor cortex. A light and electron microscopy study. J Comp Neurol 153:77-106. CrossRef Medline

Suter BA, O'Connor T, Iyer V, Petreanu LT, Hooks BM, Kiritani T, Svoboda K, Shepherd GMG (2010) Ephus: multipurpose data acquisition software for neuroscience experiments. Front Neural Circuits 4:100. CrossRef Medline

Takeuchi D, Hirabayashi T, Tamura K, Miyashita Y (2011) Reversal of interlaminar signal between sensory and memory processing in monkey temporal cortex. Science 331:1443-1447. CrossRef Medline

Tlamsa AP, Brumberg JC (2010) Organization and morphology of thalamocortical neurons of mouse ventral lateral thalamus. Somatosensory and motor research 27:34-43. CrossRef Medline

Weiler N, Wood L, Yu J, Solla SA, Shepherd GMG (2008) Top-down laminar organization of the excitatory network in motor cortex. Nat Neurosci 11:360-366. CrossRef Medline

Yu J, Anderson CT, Kiritani T, Sheets PL, Wokosin DL, Wood L, Shepherd GMG (2008) Local-circuit phenotypes of layer 5 neurons in motorfrontal cortex of YFP-H mice. Front Neural Circuits 2:6. Medline 